\title{
Rac1 plays an essential role in axon growth and guidance and in neuronal survival in the central and peripheral nervous systems
}

\author{
Zhong L. Hua ${ }^{1,5}$, Francesco E. Emiliani ${ }^{1}$ and Jeremy Nathans ${ }^{1,2,3,4^{*}}$
}

\begin{abstract}
Background: Rac1 is a critical regulator of cytoskeletal dynamics in multiple cell types. In the nervous system, it has been implicated in the control of cell proliferation, neuronal migration, and axon development.

Results: To systematically investigate the role of Rac1 in axon growth and guidance in the developing nervous system, we have examined the phenotypes associated with deleting Rac1 in the embryonic mouse forebrain, in cranial and spinal motor neurons, in cranial sensory and dorsal root ganglion neurons, and in the retina. We observe a widespread requirement for Racl in axon growth and guidance and a cell-autonomous defect in axon growth in $\mathrm{RaCl}^{-1-}$ motor neurons in culture. Neuronal death, presumably a secondary consequence of the axon growth and/or guidance defects, was observed in multiple locations. Following deletion of Rac1 in the forebrain, thalamocortical axons were misrouted inferiorly, with the majority projecting to the contralateral thalamus and a minority projecting ipsilaterally to the ventral cortex, a pattern of misrouting that is indistinguishable from the pattern previously observed in Frizzled $3^{-/-}$and $\mathrm{Cels} \mathrm{3}^{-/-}$forebrains. In the limbs, motor-neuron-specific deletion of Rac1 produced a distinctive stalling of axons within the dorsal nerve of the hindlimb but a much milder loss of axons in the ventral hindlimb and forelimb nerves, a pattern that is virtually identical to the one previously observed in Frizzled $3^{-1-}$ limbs.
\end{abstract}

Conclusions: The similarities in axon growth and guidance phenotypes caused by Rac1, Frizzled3, and Celsr3 loss-offunction mutations suggest a mechanistic connection between tissue polarity/planar cell polarity signaling and Rac1-dependent cytoskeletal regulation.

Keywords: Planar cell polarity, Brain, Spinal cord, Retina, Motor neuron, Sensory neuron

\section{Background}

Small GTPases act as molecular toggle switches, cycling between active GTP-bound and inactive GDP-bound states to regulate a wide variety of intracellular processes in response to extracellular signals [1]. Rac1, a widely expressed member of the Rho GTPase family, controls actin dynamics and plays an essential role in cell proliferation and migration in multiple contexts [2].

In mice, constitutive deletion of Rac1 leads to early embryonic lethality [3]. However, selective deletion of

\footnotetext{
*Correspondence: jnathans@jhmi.edu

'Department of Molecular Biology and Genetics, Johns Hopkins University

School of Medicine, Baltimore, MD 21205, USA

${ }^{2}$ Department of Neuroscience, Johns Hopkins University School of Medicine,

Baltimore, MD 21205, USA

Full list of author information is available at the end of the article
}

Rac1 in the anterior neural tube starting at embryonic day (E)8.5 permits survival until birth, and at late gestation, these embryos show an absence of the anterior commissure, a failure of the corpus callosum and hippocampal commissure to cross the midline, and defects in corticothalamic and thalamocortical projections [4]. Loss of Rac1 also leads to a reduction in the proliferation and survival of neural progenitors and a severe defect in tangential migration of inhibitory interneurons $[5,6]$. Selective deletion of Rac1 in the cerebral cortex blocks midline crossing of axons in the corpus callosum and anterior commissure, but there is little or no effect on the development of the corticospinal, corticothalamic, and thalamocortical tracts [7].

The tissue polarity/planar cell polarity (PCP) signaling system is one of several cell-cell signaling systems that 
control axon guidance. PCP signaling is conserved from insects to mammals, and it has been most intensively studied in the context of epithelia, where it establishes and maintains polarity within the plane of the epithelium relative to global anatomic structures. PCP signaling appears to converge on the cytoskeleton, and a variety of experiments in the context of convergent extension and inner ear sensory hair cell development suggest the direct or indirect involvement of small GTPases as effectors of PCP signaling [8-12].

Mutations in either of two core PCP genes, Frizzled $(F z) 3$ and Celsr3, cause profound and virtually identical defects in axon guidance in mice, including defects in corticothalamic, thalamocortical, nigrostriatal, and spinal sensory axon tracts [13-19]. We recently conducted a comprehensive analysis of axonal development in both the central and peripheral nervous systems in $\mathrm{Fz}^{-/-}$ mice $[17,18]$, and we were intrigued by the potential similarities between the $\mathrm{Fz}^{-/-}$axon guidance defects and the axon guidance defects reported by Chen et al. [4] and Kassai et al. [7] in forebrain-specific Rac1 knockout mice. Here we present a comprehensive analysis of axonal development in conditional mutants of Rac1, including the first analysis of the Rac1 mutant phenotype in sensory and motor neurons. We have used the same methodologies that were used in our earlier studies of $F z 3$ mutants, and the resulting comparisons of $F z 3$ and Rac1 loss-of-function phenotypes reveal several striking similarities.

\section{Results}

\section{Defects in forebrain axon tracts in Foxg1-Cre; $\mathrm{Rac}^{\mathrm{CKO} /-}$ embryos}

To compare axon growth and guidance phenotypes produced by loss of Rac1 with our earlier studies of $F z 3$ lossof-function mutations in the forebrain, we immunostained coronal sections of E18.5 Foxg1-Cre; Rac1 ${ }^{C K O /-}$ and control $\mathrm{Racl}^{\mathrm{CKO} /+}$ brains for neurofilament and compared them to an analogous set of coronal sections from Foxg1$\mathrm{Cre} ; \mathrm{Fz} 3^{C K O /-}$ embryos, shown in Figures 1 and 2 of Hua et al. [18]. (Foxg1-Cre is expressed prior to E10.5 in the anterior neural tube, leading to Cre-mediated recombination in all or nearly all CNS cell types in the developing telencephalon). Figure 1a-c' shows that Foxg1-Cre; $R$ $a c 1^{C K O /-}$ forebrains are smaller than littermate controls and they exhibit axon growth and guidance defects that closely resemble the defects seen in Foxg1-Cre; $F z 3^{C K O /-}$ forebrains (compare to Figure 2B-B" of Hua et al. [18]). In particular, Fig. 1a'-c' shows that in Foxg1-Cre;Rac1 ${ }^{\text {CKO/- }}$ forebrains the lateral ventricles are enlarged, axons are missing from the subcortical zone, the corpus callosum is misrouted away from the midline, axons are missing from the striatum, and the anterior commissure is missing. Among thalamocortical axons, none traverses the striatum to innervate the cortex. Instead, a majority of these axons are misrouted so that they project to the contralateral thalamus, resulting in a dense U-shaped axon tract along the inferior border of the thalamus. The remaining minority of thalamocortical axons are misrouted to the ventral ipsilateral cortex. The misrouting of thalamocortical axons in Foxg1-Cre;Rac1 ${ }^{\mathrm{CKO} /-}$ brains is indistinguishable from the phenotype observed in Foxg1-Cre;Fz3 ${ }^{\mathrm{CKO} /-}$ brains (compare Fig. 1c' with Figures 1 and 2 in Hua et al. [18]).

Inhibitory interneurons in the cerebral cortex are born in the medial ganglionic eminence and migrate tangentially across the cortex between E12 and E16 [20]. Using Lhx6.1 and GAD67 as markers at E16.5 and E18.5, Chen et al. [4] observed a nearly complete absence of interneurons in the cerebral cortex in Foxg1-Cre;Rac1 ${ }^{\text {CKO/CKO }}$ embryos. Using calbindin as a marker for a subset of interneurons, Fig. 1d-g' confirms those results by showing that, at E13.5, migrating interneurons are present in the control cortex but are absent from the Foxg1-Cre;R$a c 1^{\text {CKO/- }}$ cortex.

To test the possibility that combined haplo-insufficiency for $F z 3$ and $R a c 1$ might reveal a genetic interaction, we compared $\mathrm{Racl}^{\mathrm{CKO} /+}$ vs. Foxg1-Cre;Rac1 ${ }^{\mathrm{CKO} /+} ; \mathrm{Fz}^{+/-}$coronal sections of E18.5 brains immunostained for neurofilament. Heterozygous deletion of either $F z 3$ or $R a c 1$ has no detectable effect on brain size or the pattern of neurofilament staining ([13, 14]; Fig. 1a-c, h-j). However, heterozygous deletion of both $F z 3$ and Rac1 in the forebrain (Foxg1-Cre; $\mathrm{Racl}^{\mathrm{CKO} /+}{ }_{;} \mathrm{Fz}^{+/-}$) results in an absence of the corpus callosum and a brain that is reduced to a size intermediate between wild type (WT) controls and Foxg1-Cre;Rac1 ${ }^{\mathrm{CKO} /-}$ (Fig. 1h-j'; compare to Fig. 1a-c'). In the Foxg1-Cre; $\mathrm{Racl}^{\mathrm{CKO} /+}{ } \mathrm{Fz}^{+/-}$brain, the axons that would normally comprise the corpus callosum collect adjacent to the midline, a defect that is seen in a variety of axon guidance mutants [21]. This genetic interaction is suggestive of a mechanistic link between $R a c 1$ and $F z 3$ function, although it is also possible that it represents an additive effect in a system that is sensitive to genetic perturbation.

\section{Survey of peripheral nerve defects in Olig2-Cre; $\mathrm{Rac}^{\mathrm{CKO} /-}$ embryos}

To broadly survey peripheral nerve phenotypes caused by loss of Rac1, we visualized axons in whole-mount E11.5 Olig2-Cre; Rac1 ${ }^{\mathrm{CKO} /-}$ embryos by immunostaining for neurofilament (Fig. 2a-d'). Olig2-Cre is expressed in many cranial and spinal motor neurons beginning at E9.5 [22-25]. This analysis revealed a severe thinning of the VIth, XIIth, C1 segmental, and phrenic nerves in Olig2Cre; Rac1 ${ }^{C K O /-}$ embryos, a set of nerves that partially overlaps the set that are thinned in $\mathrm{Fz}^{-/-}$and Olig2$\mathrm{Cre} ; \mathrm{Fz} 3^{\mathrm{CKO} /-}$ embryos (compare Fig. 2a-c' to Figures 1 and 6 in Hua et al. [17]). Whole-mount neurofilament 


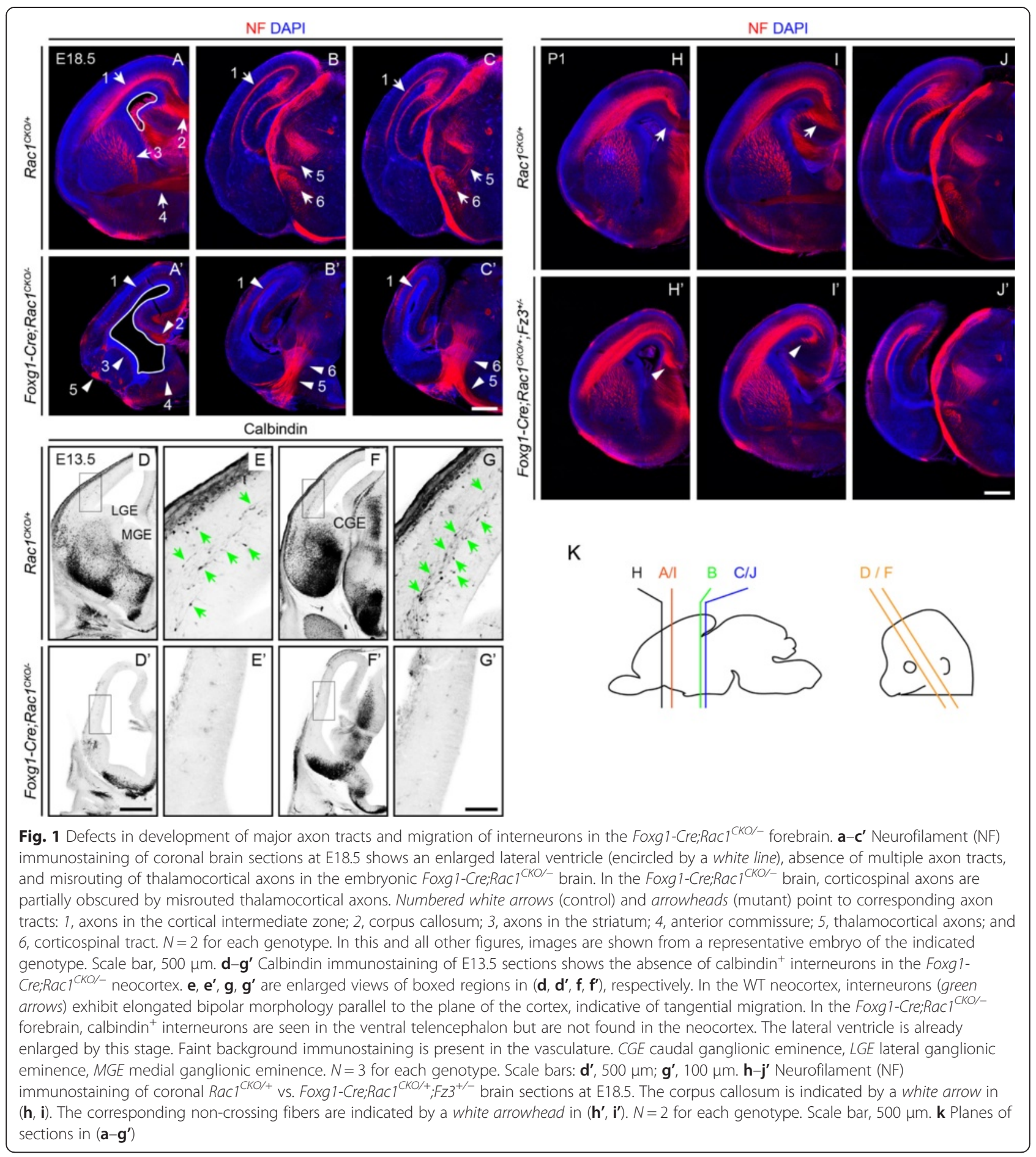

staining of Olig2-Cre;Rac1 ${ }^{C K O /-}$ fore- and hindlimbs at E13.5 shows a severe reduction in the diameter of the dorsal nerve and a more modest reduction in the diameter of the ventral nerve in the hindlimb, with only a modest reduction in the diameter of both dorsal and ventral nerves in the forelimb (Fig. 2e-h'). Among these four nerves, the dorsal nerve in the hindlimb also showed the greatest thinning in $\mathrm{Fz}^{-/-}$and Olig2$\mathrm{Cre} ; \mathrm{Fz} 3^{\mathrm{CKO} /-}$ embryos [17].

To distinguish motor vs. sensory axon contributions to the peripheral nerve defects, the $H b 9-G F P$ reporter was used to selectively visualize cranial and spinal motor axons in Olig2-Cre; Rac1 ${ }^{C K O /-}$ and control Rac1 ${ }^{C K O /+}$ embryos (Fig. 3). This analysis revealed a complete or nearly complete loss of 


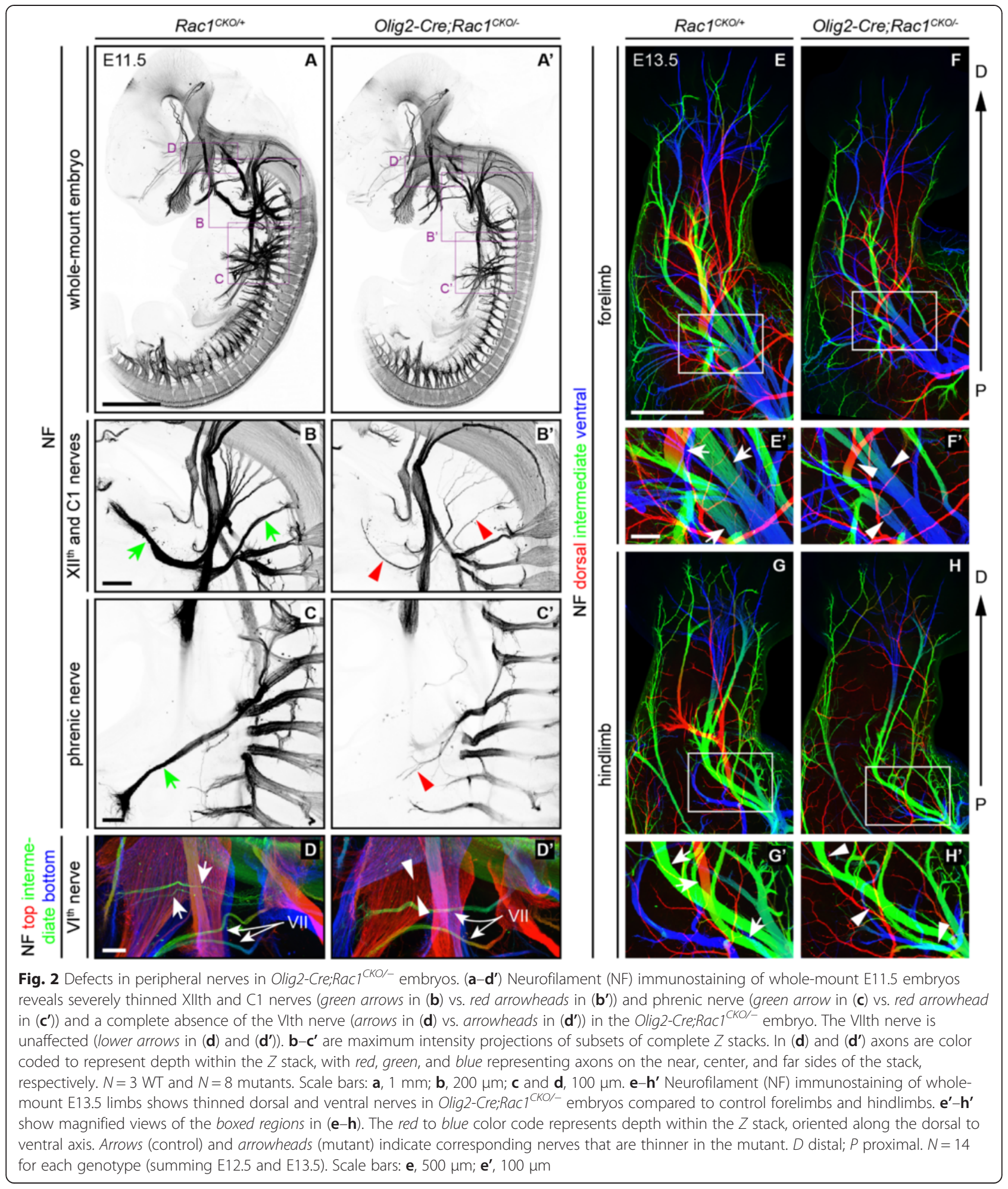

the motor component of the VIth and XIIth nerves (Fig. 3a vs. 3a' and Fig. 3d vs. 3d') and a massive reduction in the number of motor neurons in the VIth, Xth, and XIIth cranial nerve nuclei at E12.5 in Hb9-GFP;Olig2-Cre; Rac1 ${ }^{\text {CKO/- }}$ embryos (Fig. 3b vs. 3b' and Fig. 3c vs. 3c'). We did not assess motor axons within the Xth cranial nerve, but we presume that their numbers are correspondingly reduced. Axons within the VIIth nerve were Hb9-GFP negative and were unaffected in Olig2-Cre; Rac1 ${ }^{\mathrm{CKO} /-} \mathrm{em}$ bryos (Fig. 3b vs. 3b'). In the E12.5 Hb9-GFP;Olig2- 


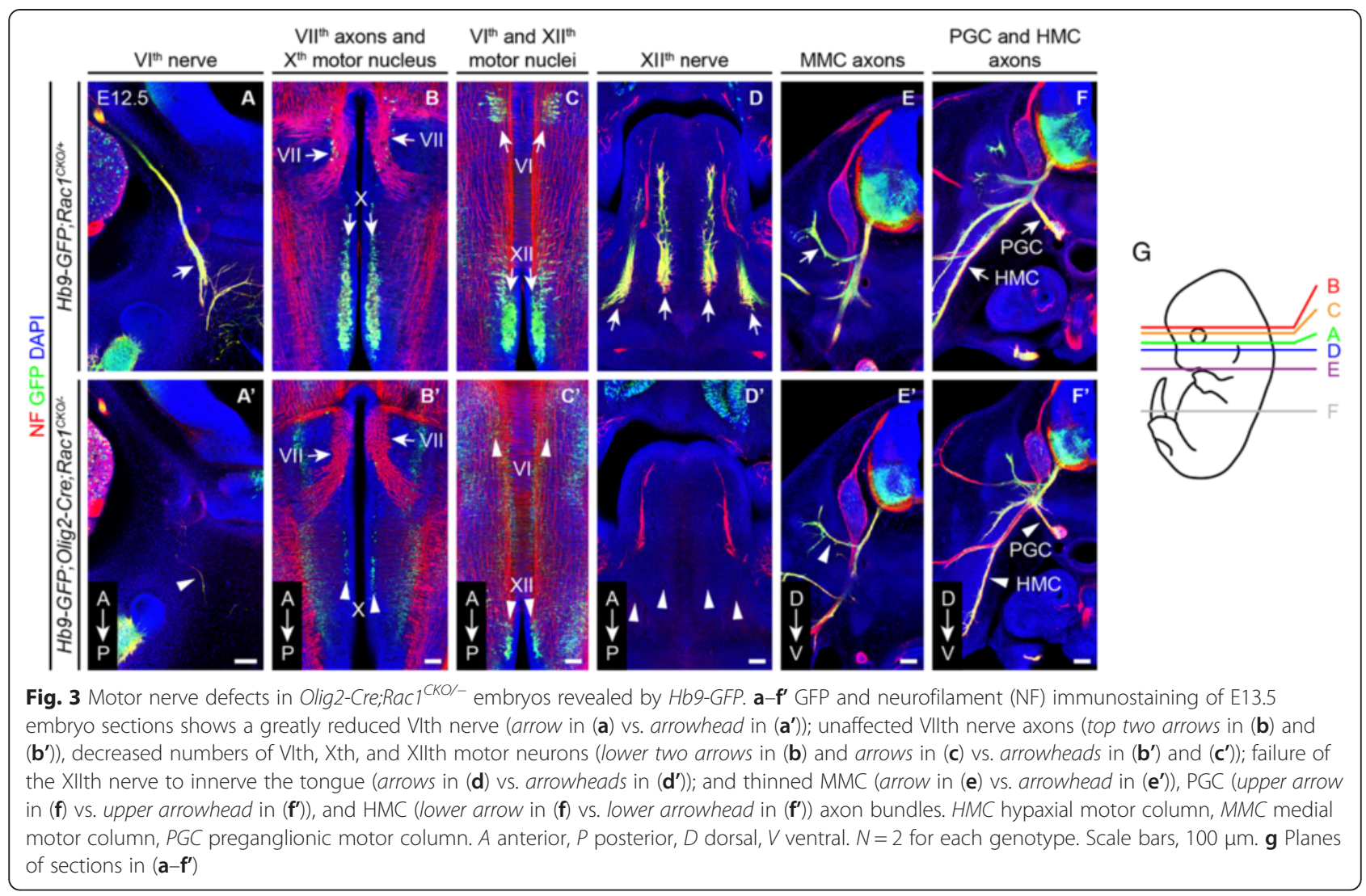

Cre;Rac1 ${ }^{\mathrm{CKO} /-}$ spinal cord, motor axons originating in the medial motor column (MMC), hypaxial motor column (HMC), and preganglionic motor column (PGC) were thinned relative to their $\mathrm{Hb}$ 9-GFP; $\mathrm{Racl}^{\mathrm{CKO} /+}$ counterparts (Fig. 3e vs 3e' and Fig. 3f vs. 3f'). These data establish an essential role for Rac1 in the development and survival of a large number of cranial and spinal motor neurons.

\section{Quantitative analysis of limb motor axon defects and} spinal motor neuron loss in Olig2-Cre; $\mathrm{Rac1}^{\mathrm{CKO} /-}$ embryos In earlier work, we quantified a distinctive axon stalling phenotype at the base of the limbs in $\mathrm{Fz}^{-/-}$embryos by measuring dorsal and ventral nerve diameters in whole mounts of neurofilament-stained limbs at E12.5 and E13.5 [17]. For the dorsal nerves, measurements were made at locations proximal and distal to the point of axon stalling (see Figure 4 in Hua et al. [17]). We have performed the same analysis on E12.5 and E13.5 Olig2-Cre;Rac1 ${ }^{\mathrm{CKO} /-}$ and WT littermates (Fig. 4a, b). At both ages, Olig2-Cre;R$a c 1^{C K O /-}$ fore- and hindlimb ventral nerve diameters were reduced, on average, to $65-73 \%$ of the diameters of littermate controls. Similarly, the Olig2-Cre; $\mathrm{Racl}^{\mathrm{CKO} /-}$ fore- and hindlimb dorsal nerve diameters proximal to the $\mathrm{Fz}^{-/-}$ stalling point were reduced, on average, to $59-69 \%$ of the diameters of littermate controls. Interestingly, the Olig2$\mathrm{Cre} ; \mathrm{Racl}^{\mathrm{CKO} /-}$ dorsal nerve diameters distal to the $\mathrm{Fz}^{-/-}$ stalling point were reduced, on average, in the forelimb to $47-53 \%$ of the control diameters and in the hindlimb to $16-21 \%$ of the control diameters. These data indicate that in Olig2-Cre; $\mathrm{Rac1}^{\mathrm{CKO} /-}$ embryos there is a severe axon stalling defect in the hindlimb dorsal nerve and a moderate axon growth defect in the three other limb nerves that were quantified in Fig. 4a, b. These patterns of nerve diameter reduction closely match the patterns observed in $\mathrm{Fz}^{-/-}$ limbs, both qualitatively and quantitatively.

Our earlier analysis of $F z 3^{-/-}$embryos showed that axon stalling leads to a secondary loss of spinal and cranial motor neurons. In the late E11.5 lumbar spinal cord, motor neuron loss was largely limited to the lateral division of the lateral motor column (LMC; Figure 5 in Hua et al. [17]). A similar analysis of Olig2-Cre; $\mathrm{Rac1}^{\mathrm{CKO} /-}$ lumbar spinal cords showed an increase in the number of apoptotic motor neurons at E11.5, as determined by immunostaining for cleaved caspase3 (Fig. 4c), and a reduction in motor neurons in both the medial and lateral divisions of the lateral motor column $\left(\mathrm{LMC}_{\mathrm{M}}\right.$ and $\left.\mathrm{LMC}_{\mathrm{L}}\right)$ relative to littermate controls (Fig. 4d-f). Cell loss in both divisions rather than a single division implies the presence of developmental defects in the Olig2-Cre; Rac1 ${ }^{\mathrm{CKO} /-}$ spinal cord that are broader than the defects in the $F z 3^{-/-}$spinal cord.

To assess the autonomy of the motor axon growth defects in Olig2-Cre;Rac1 ${ }^{\mathrm{CKO} /-}$ embryos, dissociated cells 


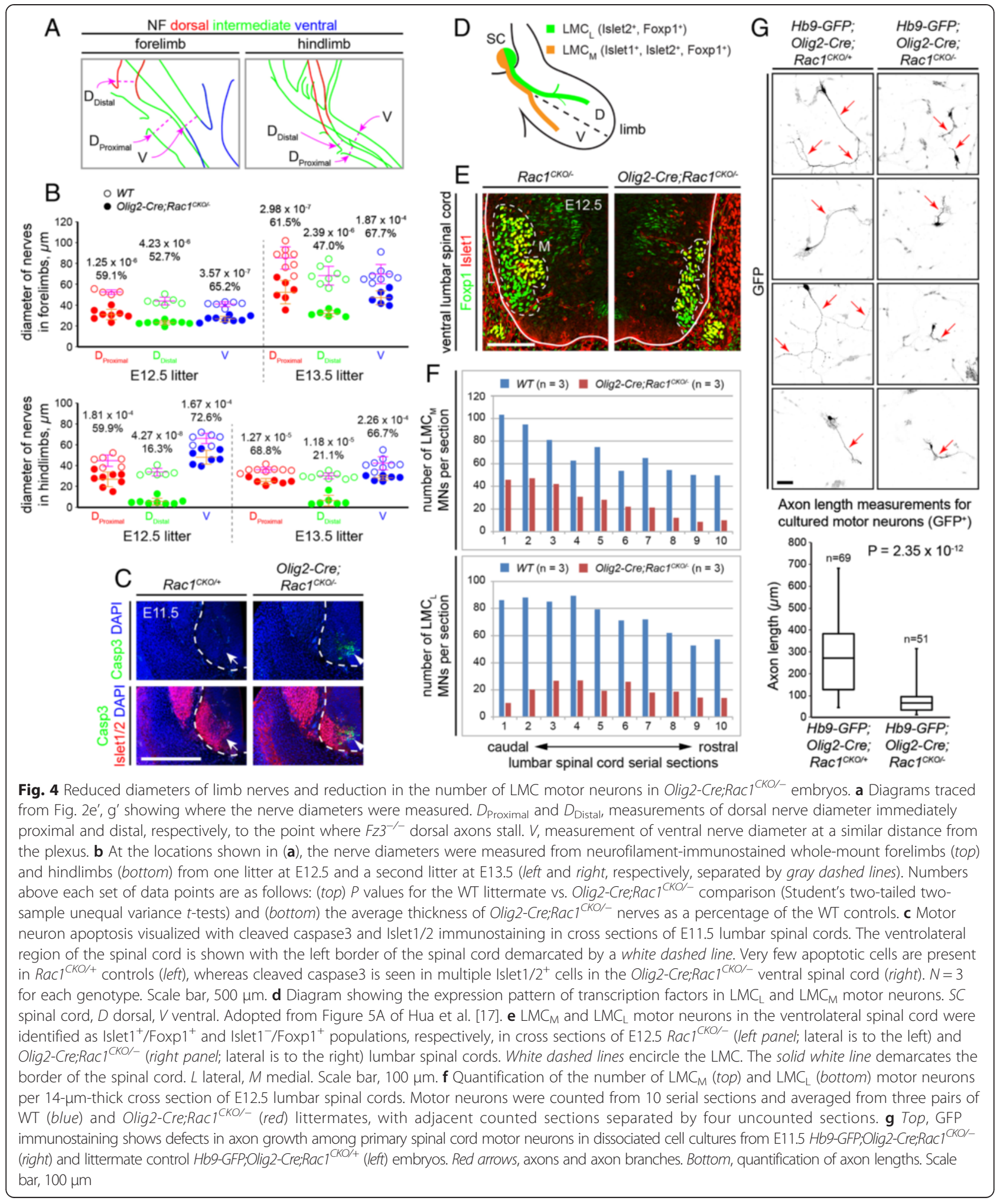

were cultured from E11.5 spinal cords of Hb9-GFP;Olig2-Cre; $\mathrm{Racl}^{\mathrm{CKO} /-}$ and littermate control Hb9-GFP;Olig2-Cre; $\mathrm{Racl}^{\mathrm{CKO} /+}$ embryos, and among $\mathrm{GFP}^{+}$neurons, axon lengths were quantified after 2 days in culture. In a sample of $51 \mathrm{Hb}$-GFP;Olig2-Cre;Rac1 ${ }^{\mathrm{CKO} /-}$ and 69 control axons, the axons of Rac1-deficient motor neurons had a mean length approximately one third of the length of the control group $\left(P<10^{-11}\right)$ (Fig. $4 \mathrm{~g}$ ). Thus, loss of 
Rac1 impairs axon growth in a cell-autonomous manner. In dissociated neuronal cultures, a similar cell-autonomous axon growth defect was observed among Rac1-deficient cerebellar granule cells [26], but no axon growth defect was observed among Rac1-deficient cerebral cortical pyramidal neurons [4]. The results of Chen et al. [4] could reflect the presence of compensating Rho family members in cortical neurons.

\section{A requirement for Rac1 in sensory neurons: defects in} dorsal root ganglia and in cranial nerves and ganglia in Wnt 1-Cre; Rac $^{\text {CKO/- }}{ }^{\text {embryos }}$

To explore the role of Rac1 in sensory neurons, which are not sites of Cre-mediated recombination by the Olig2Cre driver, we examined the phenotype of E11.5 Wnt1Cre;Rac1 ${ }^{C K O /-}$ embryos. By whole-mount neurofilament immunostaining at E11.5, Wnt1-Cre;Rac1 ${ }^{\text {CKO/- }}$ embryos exhibited severe diminutions in the IIIrd, IVth, and Vth cranial nerves and a distal stalling of the XIIth cranial nerve (Fig. 5a-d'). Additionally, E11.5 Wnt1-Cre;Rac1 ${ }^{\text {CKO/- }}$ embryos showed a reduction in the number of axons in the nerves originating in the dorsal root ganglion (DRG) and the sympathetic chain ganglia (Fig. 5e-g'). In Olig2Cre;Racl ${ }^{C K O /-}$ embryos, the IIIrd, IVth, and Vth cranial nerves were unaffected (Fig. 2a, a').

Wnt1-Cre is expressed in migrating neural crest cells, including those that form the DRG and cranial sensory ganglia [27]. As Rac1 acts in both cell migration and axon guidance, it would not be surprising to find that defects in one or both of these processes affect sensory neuron development. To assess Rac1 effects at the earliest stages of DRG development, we compared the DRG in coronal
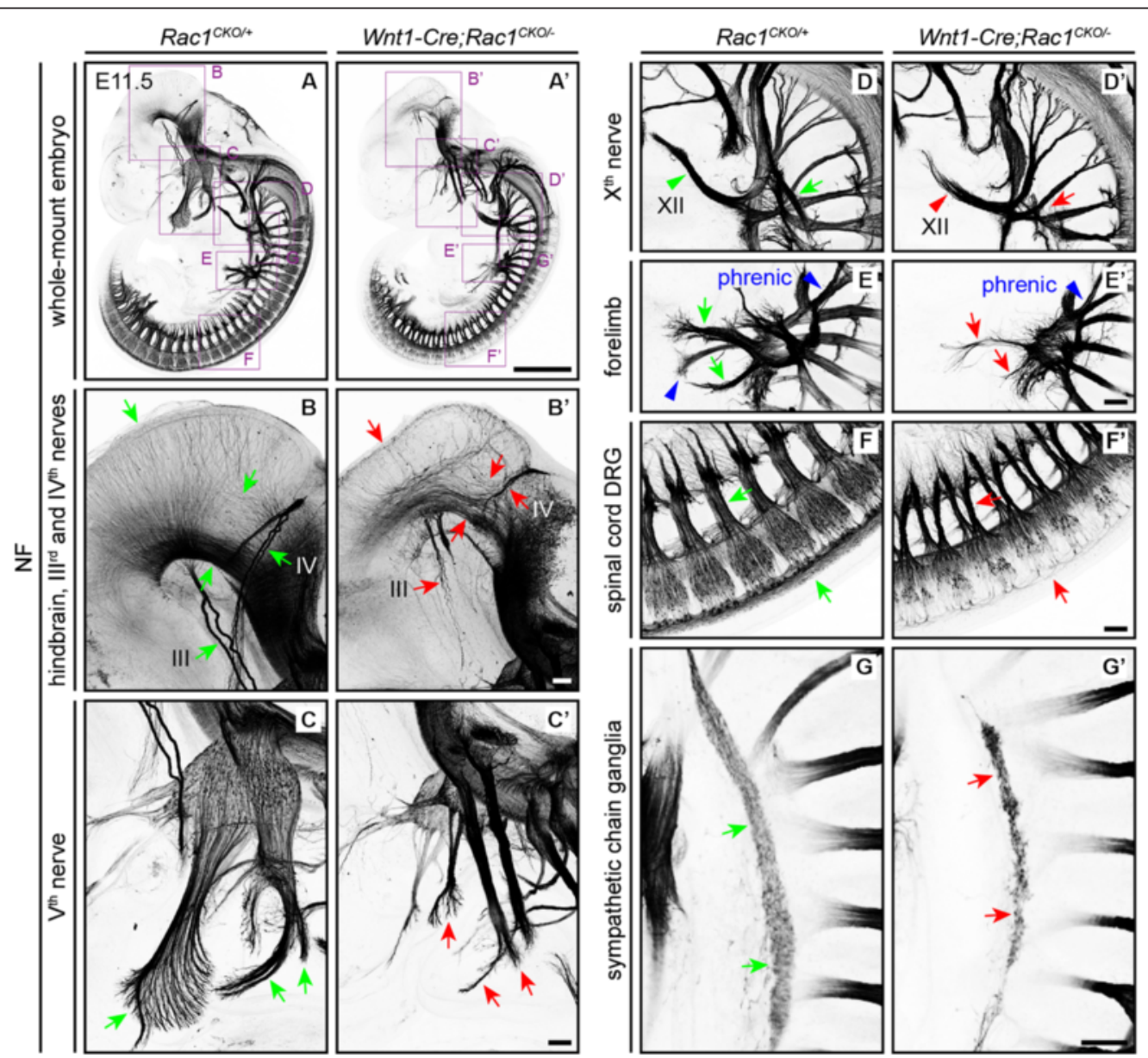

Fig. 5 Axon tract and peripheral nerve defects in Wnt1-Cre;Rac1 ${ }^{\text {CKO/- }}$ embryos. a-g' Neurofilament (NF) immunostaining of whole-mount E11.5 embryos shows that in Wnt1-Cre:Rac1 ${ }^{\text {CKO/- }}$ embryos, multiple axon tracts are aberrant including the following: diffuse axonal projections in the hindbrain and the IIIrd and IVth nerves (green arrows in (b) vs. red arrows in $\left(\mathbf{b}^{\prime}\right)$ ), the Vth nerve (green arrows in $(\mathbf{c})$ vs. red arrows in $\left(\mathbf{c}^{\prime}\right)$ ), the Xth (green arrow in (d) vs. red arrow in $\left(\mathbf{d}^{\prime}\right)$ ) and Xllth nerves (green arrowhead in (d) vs. red arrowhead in $\left(\mathbf{d}^{\prime}\right)$ ), multiple nerves in the forelimb (green arrows in (e) vs. red arrows in $\left(\mathbf{e}^{\prime}\right)$ ), and ventral axons from the DRG (green arrows in (f) vs. red arrows in $\left(\mathbf{f}^{\prime}\right)$ ). The sympathetic chain ganglia are reduced in size (green arrows in $(\mathbf{g})$ vs. red arrows in $\left(\mathbf{g}^{\prime}\right)$ ). To show the individual hindbrain axons, the neurofilament signal intensity was increased in the $(\mathbf{b})$ and $\left(\mathbf{b}^{\prime}\right)$ images. $\mathbf{d}-\mathbf{e}^{\prime}, \mathbf{g}, \mathbf{g}^{\prime}$ are maximum intensity projections of a subset of $Z$ stacks containing the entire nerves or chain ganglia. $N=3$ for each genotype. Scale bars: $\mathbf{a}^{\prime}, 1 \mathrm{~mm} ; \mathbf{b}^{\prime}-\mathbf{g}^{\prime}, 100 \mu \mathrm{m}$ 
sections of Wnt1-Cre;Rac1 ${ }^{\mathrm{CKO} /-}$ and littermate control embryos at E11.5. This comparison revealed a dramatic reduction in the size of the DRG and number of DRG neurons in the brachial and thoracic regions in Wnt1Cre; $\mathrm{Rac1}^{\mathrm{CKO} /-}$ embryos, but there was no difference between mutant and control embryos in the expression of DRG markers (Brn3a, Islet1/2, Sox10), and there was little or no difference between mutant and control embryos in the relative density of DRG neurons with activated caspase 3 at this stage (Fig. 6a-d).

In earlier work, we found that defective migration of DRG progenitors in $\mathrm{Fz}^{-/-}$embryos produces a characteristic accumulation of neurons expressing DRG markers (neurofilament, Brn3a, and Islet1/2, or Sox10) in the dorsal neural tube at E11.5 and E12.5 [17]. These cell clusters were not observed in Wnt1-Cre; Rac1 ${ }^{\mathrm{CKO} /-}$ embryos (compare Fig. 5a, a', f, f' with Figure 3 of Hua et al. [17]).
At present, it is not clear whether the primary defect in Wnt1-Cre;Rac1 ${ }^{\mathrm{CKO} /-}$ DRG development is in neural crest migration, DRG axon growth and/or guidance, or some combination of the two, since we have not identified the missing neural crest cells. However, it is apparent that DRG neurons are affected early in their development, since they are already missing from the DRG at E11.5.

\section{Defects in retinal ganglion cell axon guidance and survival in Pax6-alpha-Cre;Rac1 ${ }^{\mathrm{CKO} /-}$ and Six3-Cre;Rac1 ${ }^{\mathrm{CKO} /-}$ mice} The growth of retinal ganglion cell (RGC) axons to their central targets presents a favorable system in which to study long-range axon guidance [28]. Eliminating Rac1 predominantly in the peripheral retina beginning at $\sim \mathrm{E} 9.5$ with the Pax6-alpha-Cre driver [29] does not affect the viability or overall health of the embryo or postnatal mouse and thus permits a phenotypic analysis in
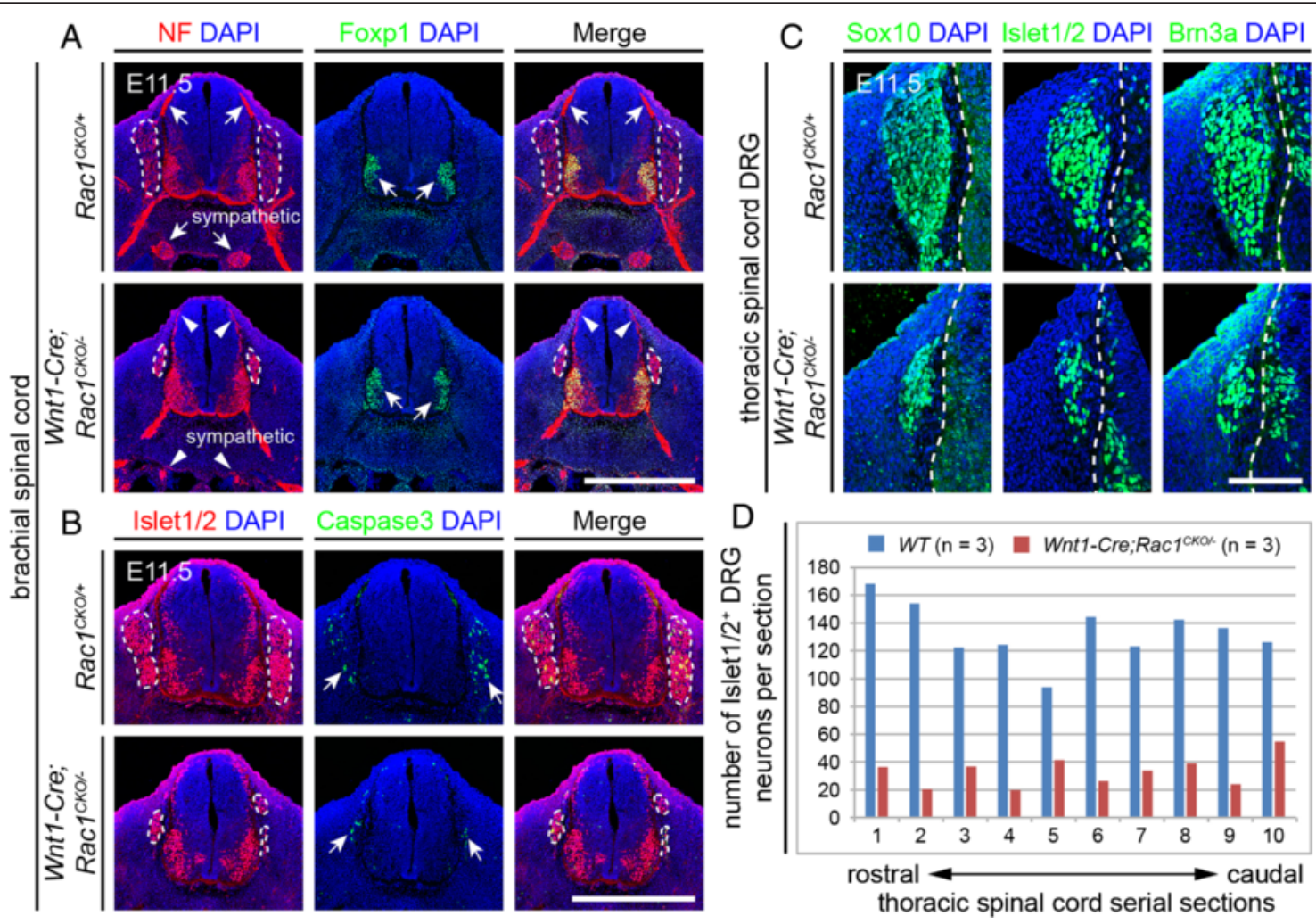

Fig. 6 Abundance of DRG neurons in Wnt1-Cre;Rac1 ${ }^{C K O /-}$ embryos. a Neurofilament (NF) and Foxp1 immunostaining of E11.5 brachial spinal cord and DRG cross sections. In the Wnt1-Cre;Rac1 ${ }^{C K O /-}$ embryo, the DRG (encircled by white dashed lines) are reduced in size, the axons projecting from the DRG to the dorsal spinal cord (upper pair of arrows vs. arrowheads) are reduced in diameter, and the sympathetic ganglia are reduced in size (lower pair of arrows vs. arrowheads in the left panels). At this age, LMC motor neurons are unaffected in Wnt1-Cre;RaC1 CKO/- embryos (arrows in middle panels). $N=2$ for each genotype. Scale bar, $500 \mu \mathrm{m}$. b Islet1/2 and cleaved caspase3 immunostaining of E11.5 brachial spinal cord and DRG cross sections showing a similar density of apoptotic cells in Rac1 ${ }^{C K O /+}$ and Wnt1-Cre;Rac1 ${ }^{C K O /-}$ DRG, which are encircled by white dashed lines and indicated by paired arrowheads in the middle panels. $N=2$ for each genotype. Scale bar, $500 \mu m$. c Loss of Rac1 does not affect differentiation of neurons in the DRG (in the center of each image), as determined by Sox10, Islet1/2, and Brn3a immunostaining of cross sections from E11.5 Wnt1-Cre;Rac1 ${ }^{\mathrm{CKO} /-}$ thoracic DRG. The lateral edge of the spinal cord, which is on the right side of each image, is delineated by dashed white lines. $N=1$ for each genotype. Scale bar, $100 \mu \mathrm{m}$. d Quantification of Islet1/2+ DRG neurons per 14- $\mu$ m-thick cross section of E11.5 thoracic DRG. DRG sensory neurons were counted from 10 serial sections and averaged from three pairs of WT control (blue) and Wnt1-Cre;Rac1 CKO/- (red) littermates, with adjacent counted sections separated by four uncounted sections 

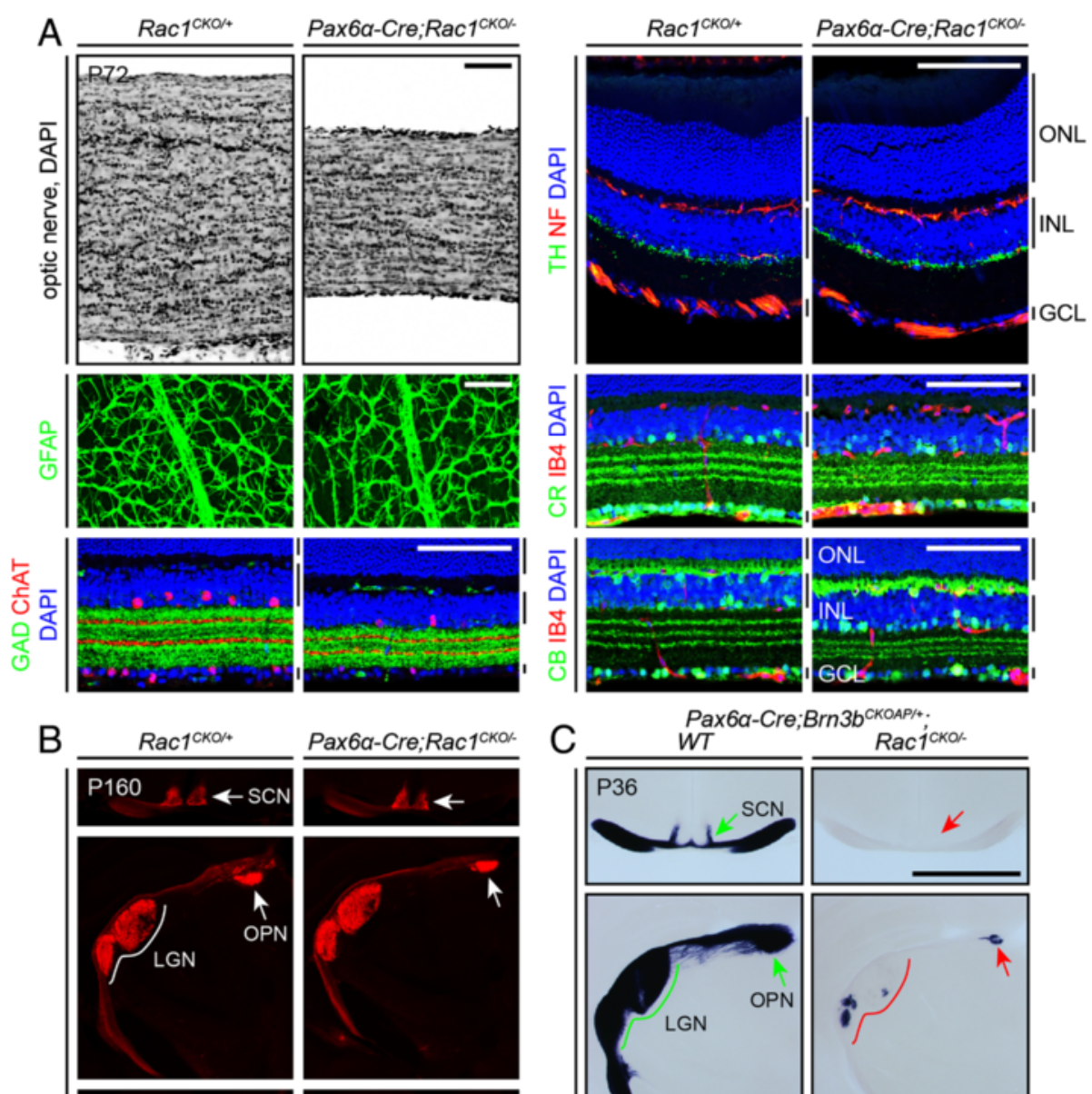

Pax6a-Cre;Rac1 ${ }^{\text {ckor }}$
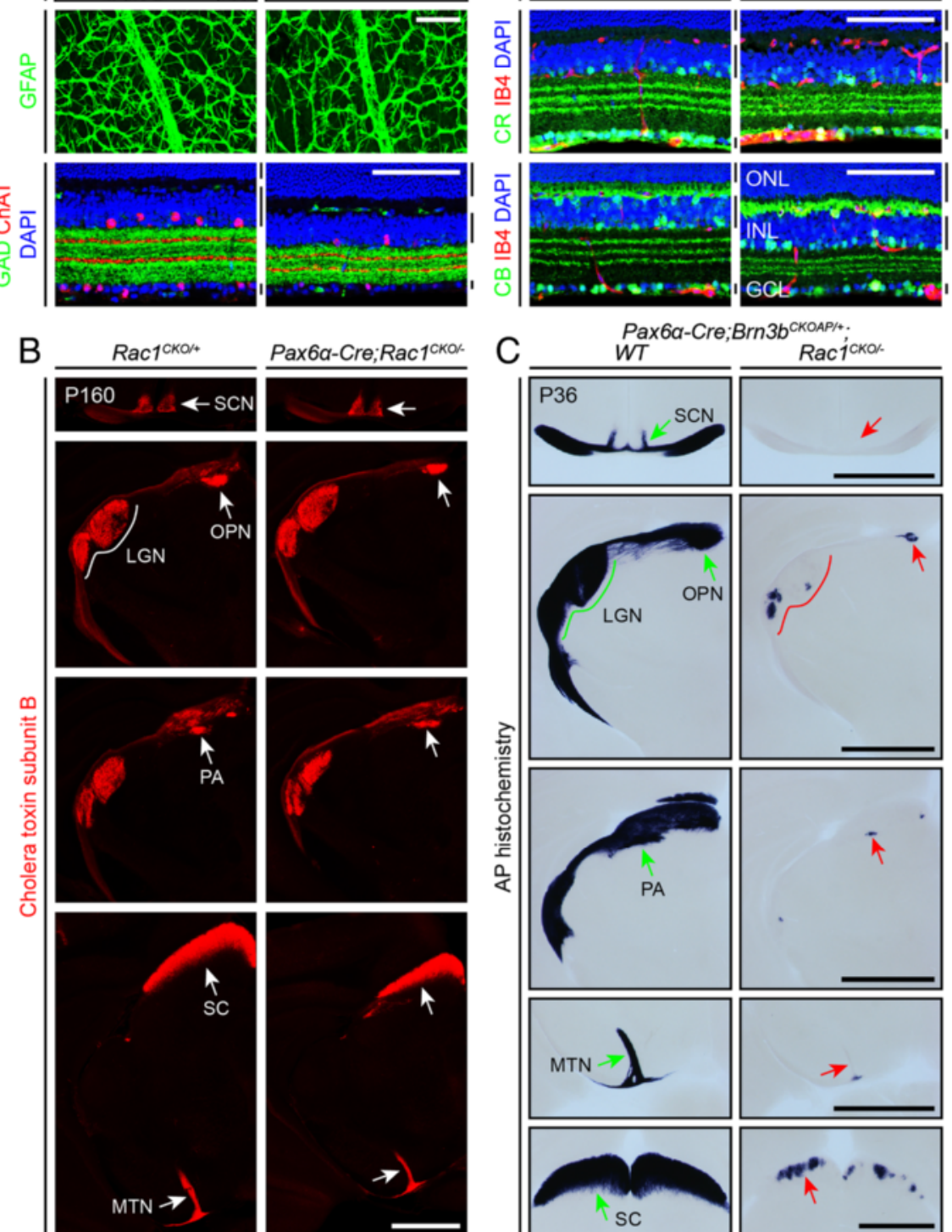

Pax6a-Cre;Brn3b
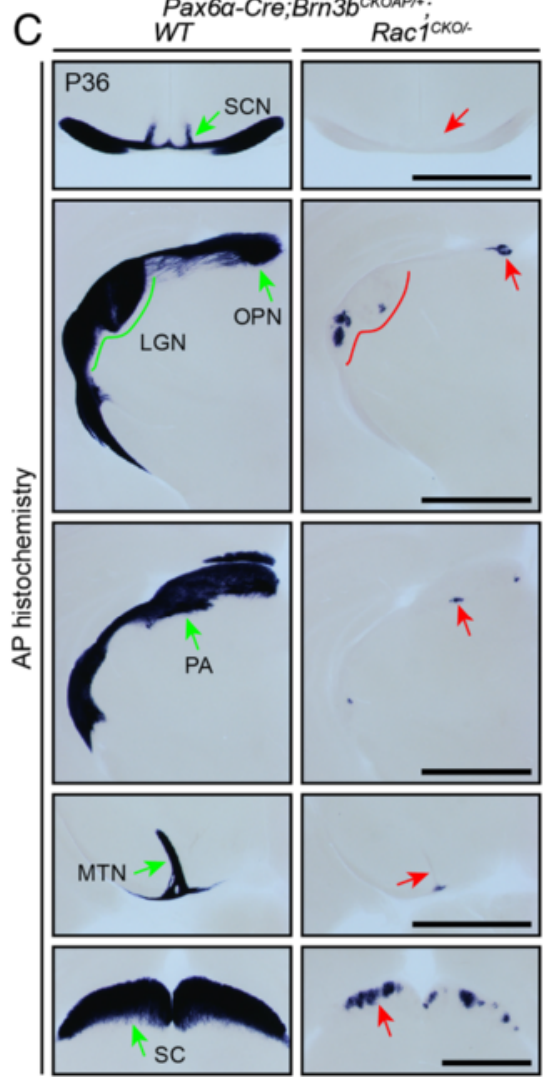

Fig. 7 (See legend on next page.) 


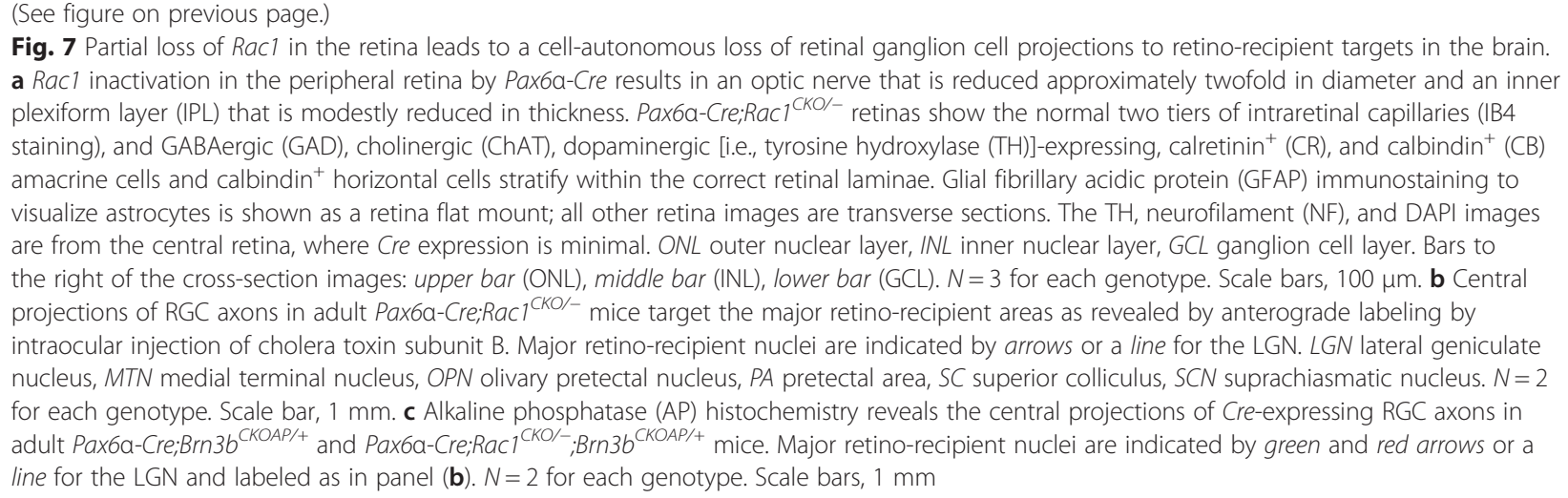

adulthood. Figure $7 \mathrm{a}$ shows that, in adult Pax6-alphaCre; $\mathrm{RaCl}^{\mathrm{CKO} /-}$ mice, the diameter of the optic nerve and the thickness of the inner retina (in the retinal periphery) are both reduced, consistent with the expression of the Pax6-alpha-Cre transgene in the periphery but not the central $\sim 50 \%$ of the retina. Within the thinned inner retina, the pattern of lamination and the locations and structures of major cell types-including cholinergic, GABAergic, dopaminergic, calbindin-expressing, and calretinin-expressing amacrine cells, and horizontal cells, blood vessels, and astroctyes-appear essentially normal (Fig. 7a). These data closely resemble the phenotype that results from the selective loss of the majority of RGCs, as observed, for example, in $\mathrm{Brn}_{3} \mathrm{~b}^{-/-}$, Math $5^{-/-}$, and $\mathrm{Brn}_{3} \mathrm{~b}^{-/-} ; \mathrm{Brn}_{3 \mathrm{C}^{-/-}}$mice [30-34].

Intraocular injection of fluorescent cholera toxin subunit $\mathrm{B}$ in adult Pax6-alpha-Cre; $\mathrm{Rac1}{ }^{\mathrm{CKO} /-}$ mice shows an essentially normal pattern of innervation of RGC axon targets, including the suprachiasmatic nucleus (SCN), lateral geniculate nucleus (LGN), olivary pretectal nucleus $(\mathrm{OPN})$, pretectal area (PA), superior colliculus (SC), and the medial terminal nucleus (MTN) (Fig. 7b). These data are consistent with the expectation (based on the pattern of Pax6-alpha-Cre expression) that RGCs within the central $\sim 50 \%$ of the retina should retain Rac1 function. To selectively visualize the axons of RGCs that had lost Rac1, we introduced a Cre-activated alkaline phosphatase $(A P)$ knock-in allele that is expressed exclusively in RGCs (Brn3b $\left.{ }^{C K O A P} ;[35]\right)$. In the peripheral retina, Pax6-alphaCre expression is predicted to lead to Cre-mediated recombination of both $R a c 1^{C K O}$ and $B r n 3 b^{C K O A P}$, simultaneously eliminating Rac1 and activating expression of $A P$ in RGCs. As seen in the left column of Fig. 7c, control brains from adult Pax6-alpha-Cre;Brn $3 b^{C K O A P /+}$ mice show AP histochemical staining in the same set of retinorecipient areas that were labeled by intraocular injection with cholera toxin subunit B (Fig. 7b). In contrast, the right column of Fig. 7c shows that brains from adult Pax6-alpha-Cre;Brn $3 b^{\mathrm{CKOAP} /+} ; \mathrm{Racl}^{\mathrm{CKO} /-}$ mice exhibit almost no AP staining in retino-recipient regions. We ascribe the occasional presence of focal zones of AP activity in retino-recipient territories to rare RGCs in which the $A P$ reporter was activated by Cre-mediated recombination but the $R a c 1^{C K O}$ allele was not recombined. These data indicate that loss of Rac1 leads to a severe deficiency in RGC axon growth, guidance, and/or RGC survival. The defect appears to be cell-autonomous since it is not corrected by neighboring $\mathrm{Racl}^{+/-} \mathrm{RGCs}$ that develop normally.

A more severe retinal phenotype is observed when Cremediated deletion of Rac1 is driven by Six3-Cre, a transgene that is expressed in all cells in the neural retina beginning at $\sim \mathrm{E} 11$ [36]. In adult Six3-Cre; $\mathrm{Rac1}{ }^{\mathrm{CKO} /-}$ retinas, the optic nerve is reduced to $<20 \%$ of the WT diameter and the inner nuclear layer and inner plexiform layer are dramatically thinned (Fig. 8a). A variety of retinal cell types are present but with substantially distorted morphologies and reduced abundances (Fig. 8a). These include cholinergic, GABAergic, dopaminergic, calbindin-expressing, and calretinin-expressing amacrine cells. Horizontal cells, marked by neurofilament and calbindin expression, appear to be almost completely absent. Neurofilament immunostaining shows accumulation of neurofilament at the inner face of the retina, and glial fibrillary acidic protein (GFAP) immunostaining of retina flat mounts shows enhanced staining in a pattern consistent with reactive astrocytes. By DAPI staining, the numbers of cells in the ganglion cell layer and the inner nuclear layer are reduced to $<50 \%$ of the WT level, but the outer nuclear layer is largely unaffected. Tracing adult RGC axons by intraocular injection of fluorescent cholera toxin subunit B in adult Six3$\mathrm{Cre}$; Rac1 ${ }^{\mathrm{CKO} /-}$ retinas shows an almost complete absence of RGC axons in retino-recipient regions (Fig. 8b). At P0, the number of RGCs is similar to the number in WT control retinas, as determined by immunostaining for transcription factor Brn3a (data not shown); earlier work demonstrated that RGC cell death secondary to axon pathfinding defects occurs at $\sim$ P10 [37]. 
A
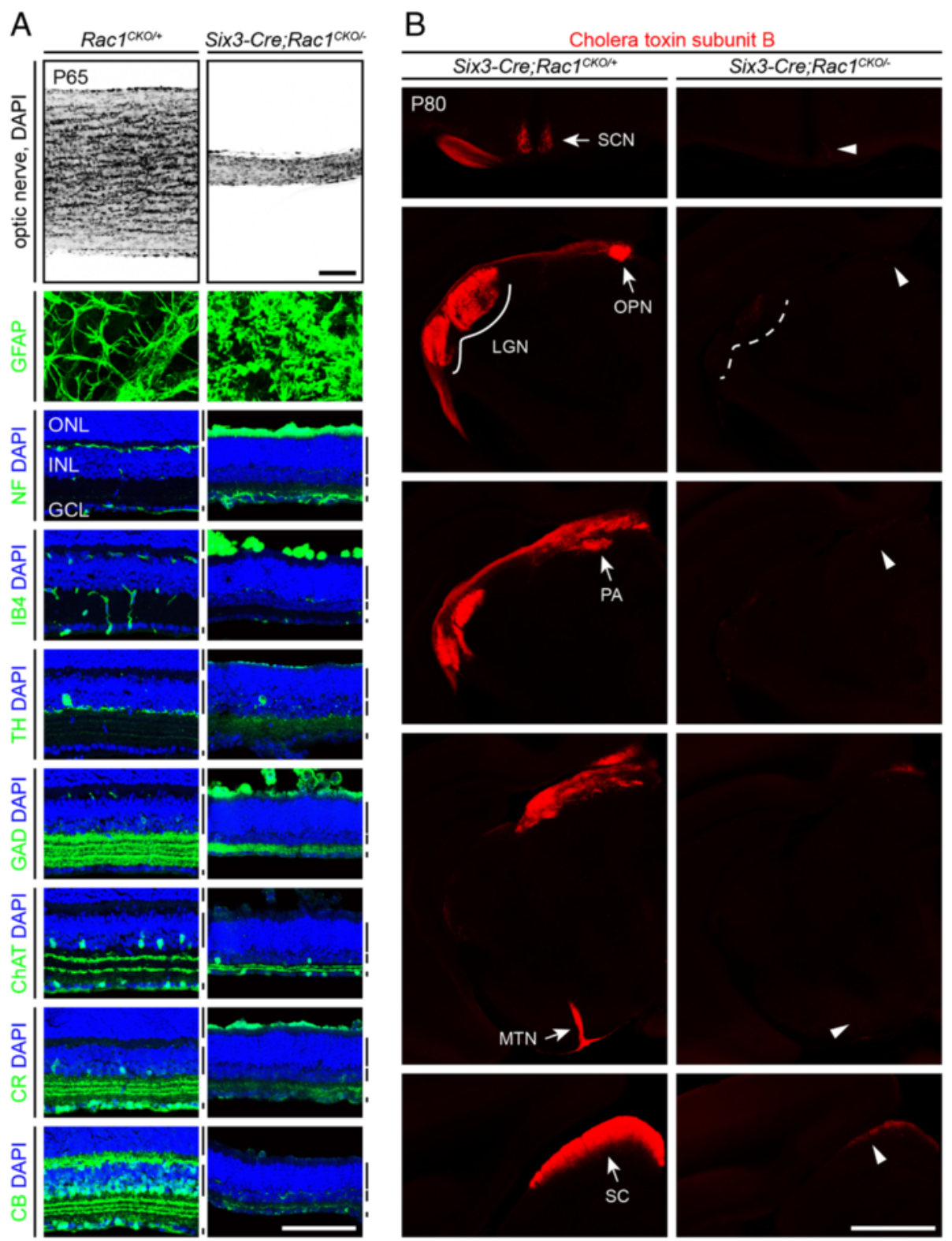

Fig. 8 Complete loss of Racl in the retina leads to a severe loss of inner retinal neurons and a nearly complete loss of retinal ganglion cell projections to retino-recipient targets in the brain. a Rac1 inactivation by Six3-Cre results in an approximately fivefold reduction in optic nerve diameter, a severe reduction in INL, IPL, and GCL thickness and inner retinal cell number, disorganization of intra-retinal capillaries (IB4), and activation of astrocytes (GFAP). The density of tyrosine hydroxylase (TH)-expressing, GABAergic (GAD), cholinergic (ChAT), calretinin ${ }^{+}(\mathrm{CR})$, and calbindin ${ }^{+}(\mathrm{CB})$ amacrine cell bodies and processes are reduced. GFAP immunostaining is shown as a retina flat mount; all other retina images are transverse sections. ONL outer nuclear layer, INL inner nuclear layer, GCL ganglion cell layer. Bars to the right of the cross-section images: upper bar (ONL), middle bar (INL), lower bar (GCL). $N=3$ for each genotype. Scale bars, $100 \mu \mathrm{m}$. b Dramatically reduced innervation of brain targets by RGCs in adult Six3-Cre;Rac1 ${ }^{C K O /-}$ mice, revealed by anterograde labeling of optic tract axons with intraocular injection of cholera toxin subunit B. LGN lateral geniculate nucleus, MTN medial terminal nucleus, OPN olivary pretectal nucleus, PA pretectal area, SC superior colliculus, SCN suprachiasmatic nucleus. N=2 for each genotype. Scale bar, 1 mm

Taken together, these data imply a central role for Rac1 in inner retinal development. Based on (1) the cell-autonomous failure of axons from Rac1-null RGCs to innervate central targets, (2) the well-established dependence of RGC survival on innervation of central targets (e.g., [37]), and (3) the well-established secondary loss of amacrine cells in mice with primary defects that lead to RGC loss (as seen in Brn3b ${ }^{-/}$, $\mathrm{Math}^{-/-}$, and Brn $3 b^{-/-} ; \mathrm{Brn}_{3} \mathrm{c}^{-/-}$mice), the simplest interpretation of the Pax6-alpha-Cre;Rac1 ${ }^{\text {CKO/- }}$ and Six3$\mathrm{Cre} ; \mathrm{Racl}^{\mathrm{CKO} / \mathrm{-}}$ retinal phenotypes is that $\mathrm{Rac1}$ is required in RGCs where it plays an essential role in axon growth. 
Under this interpretation, the observations in Figs. 7 and 8 imply that loss of Rac1 in a subset of RGCs (Pax6-alphaCre; $\mathrm{Racl}^{\mathrm{CKO} /-}$ ) leads to axon growth defects and eventual death in this RGC subset and the secondary loss of a relatively small fraction of amacrine cells, whereas loss of Rac1 in the vast majority of RGCs in Six3-Cre;Rac1 ${ }^{C K O /-}$ retinas leads to axon growth defects and eventual death in nearly all RGCs and the secondary loss of a large fraction of amacrine cells. In Six3-Cre;Rac1 ${ }^{C K O /-}$ retinas, in which Cre is expressed in retinal astrocytes, we also observe defects in postnatal retinal vascularization, which involves endothelial cell growth on an astrocyte scaffold, and this could account for part of the axon development and inner retinal phenotypes. However, these considerations do not apply to the Pax6-alpha-Cre;Rac1 ${ }^{\mathrm{CKO} /-}$ retina, as Pax6alpha-Cre is not expressed in retinal astrocytes [38].

\section{Discussion}

This study provides a systematic analysis of the consequences of Rac1 deletion in neurons in the telencephalon, cranial and spinal motor columns, sensory ganglia, and retina. In each of these neuronal populations, we observe defects in axon growth and/or guidance with loss of Rac1. Among motor neurons and retinal ganglion cells, these defects are associated with neuronal loss, consistent with the known dependence of neuronal survival on axon targeting. Additionally, we observe cell migration defects among telencephalic interneurons and a large reduction in the number of DRG neurons at E11.5. This early DRG phenotype presumably reflects a defect in the proliferation and/or migration of DRG progenitors from the neural crest. In contrast with earlier studies that used dominant negative or constitutively active mutants of Rac1 or other Rho family GTPases (for example, [39-44]), the loss-of-function approach used here does not have the potential to perturb signaling by closely related small GTPases or their effectors, and therefore, the observed phenotypes can be confidently assigned to Rac1.

\section{The breadth of Rac1 action in nervous system development}

The cell biological processes that underlie nervous system development can be roughly divided into seven general classes: (1) cell proliferation; (2) cell migration; (3) axon growth, guidance, and branching; (4) dendritic growth and branching; (5) synaptogenesis; (6) remodeling/plasticity; and (7) cell survival or death. Rac1 and related Rho GTPases play essential roles in each of these processes, as briefly summarized in points (1-7) below. (1) Rac1 in the embryonic forebrain is required for proliferation of neural progenitors $[5,6]$, and in the adult, it is required for learning-evoked neurogenesis in the hippocampus $[45,46]$. (2) In the telencephalon, Rac1 is required for tangential migration of interneurons from the medial ganglionic eminence $([4,47]$; this work), as are RhoA and Cdc42 [48]. In the rostral migratory stream, Rac1 is required for neuronal migration [49]. (3) Down-regulation of Rac1 activity by the breakpoint cluster region GTPase activating protein decreases dendritic branching in vivo and in vitro [50], and constitutive activation of Rac1 increases dendritic growth and branching in the cortex and hippocampus [51, 52]. (4) In Drosophila, Rac1 and the closely related Rho GTPases Rac2 and Mtl control axon growth, guidance, and branching $[8,53]$, and in the mouse, Rac1 is required widely in the central and peripheral nervous systems for axon growth and guidance ([4, 7]; this work). In the hippocampus, Rac1 is additionally involved in axon pruning [54]. (5) In C. elegans, the reorganization of the actin cytoskeleton and the clustering of synaptic vesicles in response to netrin signaling require Rac1 [55], and in mice, EphB signaling via the GEF Tiam requires Rac1 for excitatory spine remodeling [56]. (6) The synaptic functions of Rac1 continue throughout life, as determined by defects in hippocampal plasticity and impaired spatial memory in mice with defects in Rac1 signaling $[57,58]$. (7) Finally, Rac1 regulates cell survival by mechanisms that may include both direct and indirect effects. In the ventricular zone and subventricular zone, deletion of Rac1 leads to accelerated cell cycle exit and reduced survival of progenitors, an effect that may reflect Rac1 regulation of cell cycle progression and apoptosis $[5,6]$. Among cranial and spinal motor neurons and RGCs, cell death may be secondary to defects in axon growth and guidance (this work).

\section{Comparison of Rac1 and Fz3/Celsr3 phenotypes}

As noted in the "Background" section, the initial impetus for this study was to compare Rac1 and Fz3 phenotypes. With these two phenotypes now defined in detail using the same methodologies, it is apparent that they share a number of features $([4,7,13,14,17,18]$, this work). Most prominently, the distinctive misrouting of thalamocortical axons-with the majority projecting to the contralateral thalamus and a minority projecting to the ventral cortex-is virtually identical in Foxg1-Cre; $\mathrm{Rac1}{ }^{\mathrm{CKO} /-}, \mathrm{Fz}^{-/-}$, and $\mathrm{Celsr}^{-1-}$ embryos, as well as in Foxg1-Cre; Fz3 $3^{\mathrm{CKO} /-}$ and Foxg1-Cre;Celsr $3^{C K O / C K O}$ embryos $[15,16]$, suggesting that there may be a stereotyped default pathway for these axons if they do not traverse the normal route through the internal capsule. Mutations in Rac1, Fz3, and Celsr3 also lead to a loss of the corticospinal tract, the corticothalamic tract, and the anterior commissure. However, the loss of the corpus callosum in Foxg1-Cre;Rac1 ${ }^{C K O /-}$ embryos is not seen in $\mathrm{Fz}^{-/-}$or Celsr3 $3^{-/-}$embryos, where the corpus callosum is only mildly affected. Motorneuron-specific loss of Rac1 in Olig2-Cre;Rac1 $1^{\mathrm{CKO} /-}$ 
embryos produces a distinctive stalling of axons within the dorsal nerve of the hindlimb but a much milder loss of axons in the ventral hindlimb nerve and in forelimb nerves, a pattern that is virtually identical to the one previously observed in $\mathrm{Fz}^{-/-}$limbs. A comparison between the Olig2-Cre;Rac1 ${ }^{\mathrm{CKO} /-}$ and Olig2-Cre; $F 3^{C K O /-}$ phenotypes shows generally similar effects on cranial motor nerve axons and motor nuclei, but among different nuclei, the severity differs between the two genotypes. For example, a comparison of Fig. $2 \mathrm{~b}$ and $2 \mathrm{~b}$ ' in this work with Figure 1B and B' of Hua et al. [17] shows a more severe loss of axons in the XIIth cranial nerve and adjacent $\mathrm{C} 1$ spinal nerve in the Olig2-Cre;Rac1 ${ }^{\mathrm{CKO} /-}$ embryo compared to the $F z 3^{-/-}$embryo.

Evidence for an interaction between PCP signaling-or, more generally, noncanonical Wnt signaling-and Rho family GTPases comes largely from studies of epithelial polarity in Drosophila and morphogenetic cell movements in Xenopus and zebrafish (reviewed in [59]). Early work based on dominant negative mutants and ectopic expression demonstrated a role for Rho family GTPases in establishing the cytoskeletal organization that underlies PCP-based polarity $[60,61]$ Later work, including experiments with loss-of-function alleles, implied that the relationship between PCP signaling and Rho GTPases may be indirect, with each representing a distinct pathway of information flow that converges on the cytoskeleton [8-10, 62]. Similar interpretations may apply to experiments with mammalian epithelia, in the context of directed cell movements and asymmetry in terminally differentiated cells $[11,63]$.

At present, data regarding the mechanism of Fz3/Celsr3 signaling in axon growth and guidance are limited. Aside from the experiments reported here, we are not aware of any experiments that have examined a possible relationship between Rho family GTPases and Fz3/Celsr3 function in axon guidance. Based on pharmacologic experiments in embryonic spinal cord explants, Frizzled-mediated guidance appears to be under the control of atypical protein kinase $C$ zeta and phosphatidylinositol-3-kinase [64]. With respect to extrapolations from PCP mechanisms in epithelia, it is possible that axon guidance mechanisms are significantly different, since epithelial polarity depends on the core PCP proteins Vangl1 and Vangl2, whereas recent work suggests that axon guidance does not [19]. Additionally, the rapid extension and retraction of filopodia that accompany the exploratory movements of growth cones suggest that axon guidance may utilize PCP protein complexes that are more labile than the ones formed between epithelial cells. Interestingly, the work of Onishi et al. [65] has found a correlation between endocytic recycling of Fz3 at filopodial tips, Fz3 phosphorylation, and growth cone guidance. These data, together with the known role of Rho GTPases in regulating actin dynamics in growth cones [66], suggest that one potential mechanistic link between
Rho family GTPases and Fz3 could be at the level of local regulation of actin polymerization/depolymerization in filopodia.

\section{Conclusions}

The experiments reported here indicate a widespread requirement for Rac1 in axon growth and guidance and a cell-autonomous defect in axon growth in $\mathrm{Racl}^{-/-}$motor neurons in culture. Following deletion of $R a c 1$ in the forebrain, thalamocortical axons were misrouted in a pattern that is indistinguishable from the pattern previously observed in Frizzled $3^{-/-}$and Celsr $3^{-/-}$forebrains. In the limbs, motor-neuron-specific deletion of Rac1 produced a distinctive pattern of axon stalling that is virtually identical to the one previously observed in Frizzled $3^{-/-}$limbs. These similarities in axon growth and guidance phenotypes caused by Rac1, Frizzled3, and Celsr3 loss-offunction mutations suggest a mechanistic connection between tissue polarity/planar cell polarity signaling and Rac1-dependent cytoskeletal regulation.

\section{Methods}

\section{Mouse lines}

The following mouse lines were used: $\operatorname{Brn} 3 b^{\text {CKOAP }}$ [35], Foxg1-Cre [67], Hb9-GFP [68], Olig2-Cre [23], Pax6aCre [29], Rac1 ${ }^{\text {CKO }}$ [69], Six3-Cre [36], and Wnt1-Cre [70]. This study (protocol \#M01M469) was approved by the Institutional Animal Care and Use Committee of the Johns Hopkins Medical Institutions, and mice were housed and handled in accordance with the approved Institutional Animal Care and Use Committee guidelines of the Johns Hopkins Medical Institutions.

\section{Alkaline phosphatase (AP) histochemistry}

Throughout this work, the day of finding a copulation plug was counted as embryonic day (E)0.5, and the day when mice were born was counted as postnatal day $(\mathrm{P}) 0$. AP staining was performed on $200-\mu m$-thick brain sections from P36 mice. Mice were anesthetized with ketamine/xylazine and then sacrificed by trans-cardiac perfusion with $4 \%$ paraformaldehyde (PFA) $[w / v$, dissolved in phosphate buffered saline (PBS), pH 7.4], and brains were dissected out and further fixed in $4 \%$ PFA overnight at $4{ }^{\circ} \mathrm{C}$. Brains were embedded in $3 \%$ low melting point agarose $(w / v$, dissolved in PBS) and sectioned at $200 \mu \mathrm{m}$ on a vibratome. AP histochemistry was performed essentially as previously described $[17,18,71]$. Vibratome sections in PBS containing $2 \mathrm{mM} \mathrm{MgCl}$, were heated in a water bath at $69^{\circ} \mathrm{C}$ for $90 \mathrm{~min}$ and then equilibrated in AP-staining buffer $(0.1 \mathrm{M}$ Tris, $0.1 \mathrm{M} \mathrm{NaCl}, 50 \mathrm{mM}$ $\mathrm{MgCl}_{2}, \mathrm{pH}$ 9.5) overnight at room temperature. AP histochemistry was carried out in AP-staining buffer containing $0.34 \mu \mathrm{g} / \mathrm{ml}$ 4-nitro blue tetrazolium chloride (NBT) and $0.175 \mu \mathrm{g} / \mathrm{ml}$ 5-bromo-4-chloro-3-indolyl-phosphate (BCIP) 
(Roche Applied Science; Indianapolis, IN) for $8 \mathrm{~h}$ at room temperature with gentle horizontal shaking. Sections were dehydrated through an ethanol series and cleared with BBBA [2:1, benzyl benzoate (BB)/benzyl alcohol (BA)] (Sigma-Aldrich; St. Louis, MO) before imaging.

\section{Immunohistochemistry}

The following primary antibodies were used: mouse antiBrn3a (MAB1585; Millipore; Billerica, MA), rabbit anticalbindin D28k (CB38; Swant; Marly, Switzerland), rabbit anti-calretinin (7699/4; Swant), rabbit anti-cleaved caspase3 (9661; Cell Signaling Technology; Danvers, MA), goat anticholine acetyltransferase (ChAT) (AB144P; Millipore), rabbit anti-Foxp1 (ab16645; Abcam; Cambridge, England), mouse anti-glutamic acid decarboxylase [GAD-6; Developmental Studies Hybridoma Bank (DSHB); Iowa City, IA], rabbit anti-glial fibrillary acidic protein (GFAP) (RB-087-A; Thermo Scientific; Waltham, MA), rabbit anti-green fluorescent protein (GFP) (A11122; Life Technologies; Grand Island, NY), mouse anti-Islet1/2 (39.4D5; DSHB), rabbit anti-Islet1/2 (gift of Dr. Tom Jessell and Susan Morton, Columbia University), mouse anti-neurofilament (165 kDa, NF) (2H3; DSHB), goat anti-Sox10 (SC-17342; Santa Cruz Biotechnology; Dallas, TX), and rabbit anti-tyrosine hydroxylase (TH) (AB152; Millipore). Alexa Fluor 594-conjugated isolectin GS-IB4 (Life Technologies) was used to label blood vessels. Secondary antibodies were Alexa Fluor 488, 594, or 647 conjugated, donkey anti-goat, goat anti-mouse, or goat anti-rabbit IgG antibodies (Life Technologies).

Immunostaining was conducted as previously described $[17,18]$. For retina cryosections, the enucleated eye was immersion fixed in $4 \%$ PFA for $30 \mathrm{~min}$ at $4{ }^{\circ} \mathrm{C}$, and then, the cornea and lens were carefully removed, and the eye cup was immersion fixed in $4 \%$ PFA at $4{ }^{\circ} \mathrm{C}$ overnight, washed three times in PBS, equilibrated in $30 \%$ sucrose ( $w / v$, dissolved in PBS), embedded in optimal cutting temperature (OCT) compound (Sakura Finetek; Torrance, $\mathrm{CA})$, frozen, and sectioned at $14 \mu \mathrm{m}$ on a cryostat. For spinal cord cryosections, embryos were immersion fixed in $4 \%$ PFA at $4{ }^{\circ} \mathrm{C}$ for $2 \mathrm{~h}$, washed three times in PBS, equilibrated in $30 \%$ sucrose, embedded in OCT compound, frozen, and sectioned at $14 \mu \mathrm{m}$ on a cryostat. For vibratome sections, embryos or brains were immersion fixed in $4 \%$ PFA at $4{ }^{\circ} \mathrm{C}$ overnight, washed three times in PBS, embedded in $3 \%$ low melting point agarose, and sectioned at $120 \mu \mathrm{m}$ on a vibratome. For whole-mount E11.5 embryos, and E12.5 and E13.5 limbs, samples were immersion fixed in $4 \%$ PFA at $4{ }^{\circ} \mathrm{C}$ for $2 \mathrm{~h}$ and washed three times in PBS.

For immunostaining of 14- $\mu \mathrm{m}$-thick cryosections and $120-\mu \mathrm{m}$-thick vibratome sections, sections were blocked in blocking solution [PBS containing $0.3 \%$ Triton X-100 and $5 \%$ normal goat serum (NGS) or normal donkey serum (NDS)] at room temperature for $1 \mathrm{~h}$ and incubated with primary antibody in blocking solution at $4{ }^{\circ} \mathrm{C}$ overnight. Sections were then washed five times in PBST (PBS containing $0.3 \%$ Triton X-100) and incubated with secondary antibody in blocking solution at room temperature for $1 \mathrm{~h}$ (cryosections) or at $4{ }^{\circ} \mathrm{C}$ overnight (vibratome sections). Sections were then washed five times in PBST and mounted with Fluoromount-G (Southern Biotech; Birmingham, AL).

For immunostaining of whole-mount embryos and limbs, samples were first incubated in Dent's Bleach $\left[10 \% \mathrm{H}_{2} \mathrm{O}_{2}\right.$, $13.3 \%$ dimethyl sulfoxide (DMSO), $53.3 \%$ methanol] at $4{ }^{\circ}$ $\mathrm{C}$ for $24 \mathrm{~h}$, washed with methanol five times, and fixed in Dent's Fix (20\% DMSO, $80 \%$ methanol) at $4{ }^{\circ} \mathrm{C}$ overnight. Samples were washed in PBS three times, incubated with primary antibody in blocking solution (20 \% DMSO, $75 \%$ PBST, $5 \%$ NGS, $0.025 \%$ sodium azide) at room temperature for 5-7 days with gentle end-over-end rotation, and then washed five times in PBST. Samples were incubated with secondary antibody in blocking solution at room temperature for 2 days with gentle end-over-end rotation and then washed five times in PBST. Samples were dehydrated in $50 \%$ methanol/PBS and then $100 \%$ methanol and cleared in BBBA.

\section{Dissociated spinal cord neuron cultures}

Individual spinal cords from E11.5 embryos were dissected in Hank's balanced salt solution (HBSS), and genotyping was performed on the remaining embryonic tissue. Spinal cords were diced, washed in HBSS, and incubated in $0.05 \%$ trypsin-EDTA for $12 \mathrm{~min}$ at $37{ }^{\circ} \mathrm{C}$, washed in DMEM with $10 \%$ heat-inactivated normal horse serum, resuspended in the same media, triturated with a fire-polished Pasteur pipette, and then filtered through a $70-\mu \mathrm{m}$ filter. Cells were plated on sterile glass coverslips coated in polyD-lysine $(20 \mu \mathrm{g} / \mathrm{ml})$ and laminin $(20 \mu \mathrm{g} / \mathrm{ml})$ at a density of 50,000 cells/coverslip in 24-well plates. For immunohistochemistry, cells were washed twice in PBS with $0.5 \mathrm{mM} \mathrm{MgCl}_{2}$ and $1 \mathrm{mM} \mathrm{CaCl}$ and fixed for $10 \mathrm{~min}$ in $4 \%$ PFA. GFP was visualized with chicken anti-GFP (GFP1020; Aves Lab; Tigard, OR). Axon lengths were analyzed using the NeuronJ plug-in for ImageJ.

\section{Cholera toxin subunit B (CTB) anterograde tracing of optic tract axons}

Adult mice were deeply anesthetized with ketamine/xylazine, and $\sim 1-2 \mu \mathrm{l} 2 \mathrm{mg} / \mathrm{ml}$ Alexa Fluor 594-conjugated cholera toxin subunit B (C-22842; Life Technologies) was intraocularly injected into the left eye of the mouse with a glass micro-needle. Four days later, mice were sacrificed by trans-cardiac perfusion, and brains were dissected out and further fixed in $4 \%$ PFA overnight at $4{ }^{\circ} \mathrm{C}$. Brains were embedded in $3 \%$ low melting point agarose and sectioned at $100 \mu \mathrm{m}$ on a vibratome. Sections were 
mounted on slides with Fluoromount-G and imaged by confocal microscopy.

\section{Microscopy and image analysis}

Samples processed for AP histochemistry were imaged using a Zeiss Stemi V11 microscope with a color Axiocam $\mathrm{CCD}$ in combination with Openlab software. Immunostained samples were imaged using a Zeiss LSM700 confocal microscope with Zen software. Images of whole mounts were acquired with a $10 \times$ air objective at $10-\mu \mathrm{m}$ intervals in the $Z$ dimension, and the entire $Z$ stack was either collapsed using maximum intensity projection or color-coded based on Z-dimension depth. BBBA-cleared embryos were positioned in custom-built metal holders consisting of a shallow triangular trough (sides: $2 \mathrm{~cm} \times$ $2 \mathrm{~cm} \times 1 \mathrm{~cm}$; and depths: $1,2,3$, or $4 \mathrm{~mm})$. The trough was filled with BBBA and coverslipped during imaging.

\section{Quantification of motor and sensory neurons, measurement of nerve diameter, and statistical analysis} The number of neurons on each cryosection was manually quantified using ImageJ software. To measure the diameter of limb motor nerves, a line perpendicular to the nerve at the designated site was drawn in Adobe Illustrator and the width of the nerve along this line was then measured. Statistical comparisons were performed in Microsoft Excel.

\footnotetext{
Abbreviations

AP: alkaline phosphatase; BBBA: benzyl benzoate and benzyl alcohol; CGE: caudal ganglionic eminence; CTB: cholera toxin subunit B; DRG: dorsal root ganglion; E: embryonic; Fz: frizzled; GCL: ganglion cell layer; GFAP: glial fibrillary acidic protein; HBSS: Hank's balanced salt solution; HMC: hypaxial motor column; INL: inner nuclear layer; IPL: inner plexiform layer; LGE: latera ganglionic eminence; LGN: lateral geniculate nucleus; LMC: lateral motor column; MGE: medial ganglionic eminence; MMC: medial motor column; MTN: medial terminal nucleus; NF: neurofilament; ONL: outer nuclear layer; OPN: olivary pretectal nucleus; P: postnatal; PA: pretectal area; PCP: planar cell polarity; PGC: preganglionic motor column; RGC: retinal ganglion cell; SC: superior colliculus; SCN: suprachiasmatic nucleus; WT: wild type.
}

\section{Competing interests}

The authors declare that they have no competing interests.

\section{Authors' contributions}

FEE planned and conducted the experiments with motor axons in dissociated cell culture and conducted some of the retina immunostaining experiments. ZLH conceived of the project and conducted all of the experiments except those noted for FEE. ZLH and JN planned the research, analyzed the data, and wrote the paper. All authors have read and approved of the final manuscript.

\section{Acknowledgements}

Supported by the Howard Hughes Medical Institute. The authors thank Dr. Chia-Yi (Alex) Kuan (Cincinnati Children's Hospital) for generously providing $\mathrm{RaC1}^{\mathrm{CKO}}$ mice and Dr. Amir Rattner for critical comments on the manuscript.

\section{Author details}

${ }^{1}$ Department of Molecular Biology and Genetics, Johns Hopkins University School of Medicine, Baltimore, MD 21205, USA. ${ }^{2}$ Department of Neuroscience, Johns Hopkins University School of Medicine, Baltimore, MD 21205, USA. ${ }^{3}$ Department of Ophthalmology, Johns Hopkins University School of Medicine, Baltimore, MD 21205, USA. ${ }^{4}$ Howard Hughes Medical
Institute, Johns Hopkins University School of Medicine, Baltimore, MD 21205 , USA. ${ }^{5}$ Present address: Rockefeller University, 1230 York Avenue, New York, NY 10065, USA.

Received: 4 June 2015 Accepted: 4 September 2015

Published online: 23 September 2015

\section{References}

1. Jaffe $A B$, Hall A. Rho GTPases: biochemistry and biology. Annu Rev Cell Dev Biol. 2005;21:247-69.

2. Ridley AJ. Rho GTPases and actin dynamics in membrane protrusions and vesicle trafficking. Trends Cell Biol. 2006;16:522-9.

3. Sugihara K, Nakatsuji N, Nakamura K, Nakao K, Hashimoto R, Otani H, et al. Rac1 is required for the formation of three germ layers during gastrulation. Oncogene. 1998;17:3427-33.

4. Chen L, Liao G, Waclaw RR, Burns KA, Linquist D, Campbell K, et al. Rac1 controls the formation of midline commissures and the competency of tangential migration in ventral telencephalic neurons. J Neurosci. 2007;27:3884-93.

5. Chen L, Melendez J, Campbell K, Kuan CY, Zheng Y. Rac1 deficiency in the forebrain results in neural progenitor reduction and microcephaly. Dev Biol. 2009:325:162-70.

6. Leone DP, Srinivasan K, Brakebusch C, McConnell SK. The rho GTPase Rac1 is required for proliferation and survival of progenitors in the developing forebrain. Dev Neurobiol. 2010;70:659-78.

7. Kassai H, Terashima T, Fukaya M, Nakao K, Sakahara M, Watanabe M, et al. Rac1 in cortical projection neurons is selectively required for midline crossing of commissural axonal formation. Eur J Neurosci. 2008;28:257-67.

8. Hakeda-Suzuki S, Ng J, Tzu J, Dietzl G, Sun Y, Harms M, et al. Rac function and regulation during Drosophila development. Nature. 2002;416:438-42.

9. Muñoz-Descalzo S, Gómez-Cabrero A, Mlodzik M, Paricio N. Analysis of the role of the Rac/Cdc42 GTPases during planar cell polarity generation in Drosophila. Int J Dev Biol. 2007:51:379-87.

10. Yan J, Lu Q, Fang X, Adler PN. Rho1 has multiple functions in Drosophila wing planar polarity. Dev Biol. 2009:333:186-99.

11. Grimsley-Myers CM, Sipe CW, Géléoc GS, Lu X. The small GTPase Rac1 regulates auditory hair cell morphogenesis. J Neurosci. 2009;29:15859-69.

12. Simões Sde M, Mainieri A, Zallen JA. Rho GTPase and Shroom direct planar polarized actomyosin contractility during convergent extension. J Cell Biol. 2014;204:575-89.

13. Wang Y, Thekdi N, Smallwood PM, Macke JP, Nathans J. Frizzled-3 is required for the development of major fiber tracts in the rostral CNS. J Neurosci. 2002;22:8563-73.

14. Wang Y, Zhang J, Mori S, Nathans J. Axonal growth and guidance defects in Frizzled3 knock-out mice: a comparison of diffusion tensor magnetic resonance imaging, neurofilament staining, and genetically directed cell labeling. J Neurosci. 2006;26:355-64.

15. Tissir F, Bar I, Jossin Y, De Backer O, Goffinet AM. Protocadherin Celsr3 is crucial in axonal tract development. Nat Neurosci. 2005;8:451-7.

16. Zhou L, Bar I, Achouri Y, Campbell K, De Backer O, Hebert JM, et al. Early forebrain wiring: genetic dissection using conditional Celsr3 mutant mice. Science. 2008:320:946-9.

17. Hua ZL, Smallwood PM, Nathans J. Frizzled3 controls axonal development in distinct populations of cranial and spinal motor neurons. eLife. 2013;2, e01482.

18. Hua ZL, Jeon S, Caterina MJ, Nathans J. Frizzled3 is required for the development of multiple axon tracts in the mouse central nervous system. Proc Natl Acad Sci U S A. 2014;111:E3005-14.

19. Qu Y, Huang Y, Feng J, Alvarez-Bolado G, Grove EA, Yang Y, et al. Genetic evidence that Celsr3 and Celsr2, together with Fzd3, regulate forebrain wiring in a Vangl-independent manner. Proc Natl Acad Sci U S A. 2014;111:E2996-3004.

20. Marín O, Rubenstein JL. A long, remarkable journey: tangential migration in the telencephalon. Nat Rev Neurosci. 2001;2:780-90.

21. Ren T, Zhang J, Plachez C, Mori S, Richards LJ. Diffusion tensor magnetic resonance imaging and tract-tracing analysis of Probst bundle structure in Netrin1- and DCC-deficient mice. J Neurosci. 2007;27:10345-9.

22. Masahira N, Takebayashi H, Ono K, Watanabe K, Ding L, Furusho M, et al. Olig2-positive progenitors in the embryonic spinal cord give rise not only to motoneurons and oligodendrocytes, but also to a subset of astrocytes and ependymal cells. Dev Biol. 2006;293:358-69. 
23. Dessaud E, Yang LL, Hill K, Cox B, Ulloa F, Ribeiro A, et al. Interpretation of the sonic hedgehog morphogen gradient by a temporal adaptation mechanism. Nature. 2007;450:717-20.

24. Chen JA, Huang YP, Mazzoni EO, Tan GC, Zavadil J, Wichterle H. Mir-17-3p controls spinal neural progenitor patterning by regulating Olig2/Irx3 crossrepressive loop. Neuron. 2011;69:721-35.

25. Chen JA, Wichterle H. Apoptosis of limb innervating motor neurons and erosion of motor pool identity upon lineage specific dicer inactivation. Front Neurosci. 2012;6:69.

26. Tahirovic S, Hellal F, Neukirchen D, Hindges R, Garvalov BK, Flynn KC, et al. Rac1 regulates neuronal polarization through the WAVE complex. J Neurosci. 2005;30:6930-43.

27. Brault V, Moore R, Kutsch S, Ishibashi M, Rowitch DH, McMahon AP, et al. Inactivation of the beta-catenin gene by Wnt1-Cre-mediated deletion results in dramatic brain malformation and failure of craniofacial development. Development. 2001;128:1253-64.

28. Erskine $L$, Herrera $E$. The retinal ganglion cell axon's journey: insights into molecular mechanisms of axon guidance. Dev Biol. 2007;308:1-14

29. Marquardt T, Ashery-Padan R, Andrejewski N, Scardigli R, Guillemot F, Gruss P. Pax6 is required for the multipotent state of retinal progenitor cells. Cell. 2001;105:43-55

30. Erkman L, McEvilly RJ, Luo L, Ryan AK, Hooshmand F, O'Connell SM, et al. Role of transcription factors Brn-3.1 and Brn-3.2 in auditory and visual system development. Nature. 1996;381:603-6.

31. Gan $L$, Xiang M, Zhou L, Wagner DS, Klein WH, Nathans J. POU domain factor Brn-3b is required for the development of a large set of retinal ganglion cells. Proc Natl Acad Sci U S A. 1996;93:3920-5.

32. Brown NL, Patel S, Brzezinski J, Glaser T. Math5 is required for retinal ganglion cell and optic nerve formation. Development. 2001;128:2497-508.

33. Wang SW, Kim BS, Ding $K$, Wang $H$, Sun D, Johnson RL, et al. Requirement for math5 in the development of retinal ganglion cells. Genes Dev. 2001;15:24-9.

34. Wang SW, Mu X, Bowers WJ, Kim DS, Plas DJ, Crair MC, et al. Brn3b/Brn3C double knockout mice reveal an unsuspected role for Brn3c in retinal ganglion cell axon outgrowth. Development. 2002;129:467-77.

35. Badea TC, Cahill H, Ecker J, Hattar S, Nathans J. Distinct roles of transcription factors brn3a and brn3b in controlling the development, morphology, and function of retinal ganglion cells. Neuron. 2009;61:852-64.

36. Furuta Y, Lagutin O, Hogan BL, Oliver GC. Retina- and ventral forebrainspecific Cre recombinase activity in transgenic mice. Genesis. 2000;26:130-2.

37. Erkman L, Yates PA, McLaughlin T, McEvilly RJ, Whisenhunt T, O'Connell SM, et al. A POU domain transcription factor-dependent program regulates axon pathfinding in the vertebrate visual system. Neuron. 2000;28:779-92.

38. Rattner A, Yu H, Williams J, Smallwood PM, Nathans J. Endothelin-2 signaling in the neural retina promotes the endothelial tip cell state and inhibits angiogenesis. Proc Natl Acad Sci U S A. 2013;110:E3830-9.

39. Jin Z, Strittmatter SM. Rac1 mediates collapsin-1-induced growth cone collapse. J Neurosci. 1997;17:6256-63.

40. Ruchhoeft ML, Ohnuma S, McNeill L, Holt CE, Harris WA. The neuronal architecture of Xenopus retinal ganglion cells is sculpted by rho-family GTPases in vivo. J Neurosci. 1999;19:8454-63.

41. Nakayama AY, Harms MB, Luo L. Small GTPases Rac and Rho in the maintenance of dendritic spines and branches in hippocampal pyramidal neurons. J Neurosci. 2000;20:5329-38.

42. Tashiro A, Yuste R. Regulation of dendritic spine motility and stability by Rac1 and Rho kinase: evidence for two forms of spine motility. Mol Cell Neurosci. 2004;26:429-40.

43. Wiens KM, Lin H, Liao D. Rac1 induces the clustering of AMPA receptors during spinogenesis. J Neurosci. 2005;25:10627-36.

44. Dietz DM, Sun H, Lobo MK, Cahill ME, Chadwick B, Gao V, et al. Rac1 is essential in cocaine-induced structural plasticity of nucleus accumbens neurons. Nat Neurosci. 2012;15:891-6.

45. Haditsch U, Anderson MP, Freewoman J, Cord B, Babu H, Brakebusch C, et al. Neuronal Rac1 is required for learning-evoked neurogenesis. J Neurosci. 2013;33:12229-41.

46. Vadodaria KC, Brakebusch C, Suter U, Jessberger S. Stage-specific functions of the small Rho GTPases Cdc42 and Rac1 for adult hippocampal neurogenesis. J Neurosci. 2013;33:1179-89.

47. Vidaki M, Tivodar S, Doulgeraki K, Tybulewicz V, Kessaris N, Pachnis V, et al. Rac1-dependent cell cycle exit of MGE precursors and GABAergic interneuron migration to the cortex. Cereb Cortex. 2012;22:680-92.
48. Katayama K, Imai F, Campbell K, Lang RA, Zheng Y, Yoshida Y. RhoA and $\mathrm{Cdc} 42$ are required in pre-migratory progenitors of the medial ganglionic eminence ventricular zone for proper cortical interneuron migration. Development. 2013;140:3139-45.

49. Hikita T, Ohno A, Sawada M, Ota H, Sawamoto K. Rac1-mediated indentation of resting neurons promotes the chain migration of new neurons in the rostral migratory stream of post-natal mouse brain. J Neurochem. 2014;128:790-7.

50. Park AR, Oh D, Lim SH, Choi J, Moon J, Yu DY, et al. Regulation of dendritic arborization by BCR Rac1 GTPase-activating protein, a substrate of PTPRT. J Cell Sci. 2012;125:4518-31.

51. Hayashi K, Ohshima T, Mikoshiba K. Pak1 is involved in dendrite initiation as a downstream effector of Rac1 in cortical neurons. Mol Cell Neurosci. 2002;20:579-94.

52. Suo L, Lu H, Ying G, Capecchi MR, Wu Q. Protocadherin clusters and cell adhesion kinase regulate dendrite complexity through Rho GTPase. J Mol Cell Biol. 2012:4:362-76.

53. Ng J, Nardine T, Harms M, Tzu J, Goldstein A, Sun Y, et al. Rac GTPases control axon growth, guidance and branching. Nature. 2002;416:442-7.

54. Riccomagno MM, Hurtado A, Wang H, Macopson JG, Griner EM, Betz A, et al. The RacGAP $\beta 2$-Chimaerin selectively mediates axonal pruning in the hippocampus. Cell. 2012;149:1594-606.

55. Stavoe AK, Colón-Ramos DA. Netrin instructs synaptic vesicle clustering through Rac GTPase, MIG-10, and the actin cytoskeleton. J Cell Biol. 2012;197:75-88.

56. Um K, Niu S, Duman JG, Cheng JX, Tu YK, Schwechter B, et al. Dynamic control of excitatory synapse development by a Rac1 GEF/GAP regulatory complex. Dev Cell. 2014;29:701-15.

57. Haditsch U, Leone DP, Farinelli M, Chrostek-Grashoff A, Brakebusch C, Mansuy IM, et al. A central role for the small GTPase Rac1 in hippocampal plasticity and spatial learning and memory. Mol Cell Neurosci. 2009:41:409-19.

58. Oh D, Han S, Seo J, Lee JR, Choi J, Groffen J, et al. Regulation of synaptic Rac1 activity, long-term potentiation maintenance, and learning and memory by BCR and ABR Rac GTPase-activating proteins. J Neurosci. 2010;30:14134-44.

59. Schlessinger $\mathrm{K}$, Hall A, Tolwinski N. Wnt signaling pathways meet Rho GTPases. Genes Dev. 2009;23:265-77.

60. Eaton S, Wepf R, Simons K. Roles for Rac1 and Cdc42 in planar polarization and hair outgrowth in the wing of Drosophila. J Cell Biol. 1996;135:1277-89.

61. Fanto M, Weber U, Strutt DI, Mlodzik M. Nuclear signaling by Rac and Rho GTPases is required in the establishment of epithelial planar polarity in the Drosophila eye. Curr Biol. 2000;10:979-88.

62. Lapébie P, Borchiellini C, Houliston E. Dissecting the PCP pathway: one or more pathways?: Does a separate Wnt-Fz-Rho pathway drive morphogenesis? Bioessays. 2011;33:759-68.

63. Habas R, Dawid IB, He X. Coactivation of Rac and Rho by Wnt/Frizzled signaling is required for vertebrate gastrulation. Genes Dev. 2003;17:295-309.

64. Wolf AM, Lyuksyutova Al, Fenstermaker AG, Shafer B, Lo CG, Zou Y. Phosphatidylinositol-3-kinase-atypical protein kinase $C$ signaling is required for Wnt attraction and anterior-posterior axon guidance. J Neurosci. 2008;28:3456-67.

65. Onishi K, Shafer B, Lo C, Tissir F, Goffinet AM, Zou Y. Antagonistic functions of Dishevelleds regulate Frizzled3 endocytosis via filopodia tips in Wntmediated growth cone guidance. J Neurosci. 2013;33:19071-85.

66. Hall A, Lalli G. Rho and Ras GTPases in axon growth, guidance, and branching. Cold Spring Harb Perspect Biol. 2010;2:a001818.

67. Hebert JM, McConnell SK. Targeting of cre to the Foxg1 (BF-1) locus mediates loxp recombination in the telencephalon and other developing head structures. Dev Biol. 2000;222:296-306.

68. Wichterle H, Lieberam I, Porter JA, Jessell TM. Directed differentiation of embryonic stem cells into motor neurons. Cell. 2002;110:385-97.

69. Glogauer M, Marchal CC, Zhu F, Worku A, Clausen BE, Foerster I, et al. Rac1 deletion in mouse neutrophils has selective effects on neutrophil functions. J Immunol. 2003;170:5652-7.

70. Danielian PS, Muccino D, Rowitch DH, Michael SK, McMahon AP. Modification of gene activity in mouse embryos in utero by a tamoxifeninducible form of Cre recombinase. Curr Biol. 1998;8:1323-6.

71. Badea TC, Wang Y, Nathans J. A noninvasive genetic/pharmacologic strategy for visualizing cell morphology and clonal relationships in the mouse. J Neurosci. 2003;23:2314-22. 